Intended as original research paper for Forensic Science International: Genetics

\title{
The HIrisPlex-S system for eye, hair and skin colour prediction from DNA: Introduction and forensic developmental validation
}

Lakshmi Chaitanya ${ }^{1}$, Krystal Breslin ${ }^{2}$, Sofia Zuñiga ${ }^{3}$, Laura Wirken ${ }^{4}$, Ewelina Pośpiech ${ }^{5}$, Magdalena Kukla-Bartoszek ${ }^{6}$, Titia Sijen ${ }^{3}$, Peter de Knijff ${ }^{4}$, Fan Liu ${ }^{1,7,8}$, Wojciech Branicki ${ }^{5,9}$, Manfred Kayser ${ }^{1 *, \#, ~}$ Susan Walsh ${ }^{2 * \#}$

${ }^{1}$ Department of Genetic Identification, Erasmus MC University Medical Centre Rotterdam, Rotterdam, The Netherlands

${ }^{2}$ Department of Biology, Indiana University Purdue University Indianapolis (IUPUI), Indiana, USA

${ }^{3}$ Division Biological Traces, Netherlands Forensic Institute, The Hague, The Netherlands

${ }^{4}$ Forensic Laboratory for DNA Research, Department of Human Genetics, Leiden University Medical Center, Leiden, The Netherlands

${ }^{5}$ Malopolska Centre of Biotechnology, Jagiellonian University, Kraków, Poland

${ }^{6}$ Faculty of Biochemistry, Biophysics and Biotechnology of the Jagiellonian University, Kraków, Poland

${ }^{7}$ Key Laboratory of Genomic and Precision Medicine, Beijing Institute of Genomics, Chinese Academy of Sciences, Beijing, China

${ }^{8}$ University of Chinese Academy of Sciences, Beijing, China

${ }^{9}$ Central Forensic Laboratory of the Police, Warsaw, Poland

\# these authors contributed equally to this work

\section{* Corresponding authors}

SW: phone +1-317-274-0593, e-mail walshsus@iupui.edu

or

MK: phone +31-10-7038073, e-mail m.kayser@erasmusmc.nl

This is the author's manuscript of the article published in final edited form as:

Chaitanya, L., Breslin, K., Zuñiga, S., Wirken, L., Pośpiech, E., Kukla-Bartoszek, M., ... Walsh, S. (n.d.). The HIrisPlex-S system for eye, hair and skin colour prediction from DNA: Introduction and forensic developmental validation. Forensic Science International: Genetics. https://doi.org/10.1016/j.fsigen.2018.04.004 


\title{
Highlights
}

- We introduce the HIrisPlex-S system for eye, hair, and skin colour prediction from DNA

- HIrisPlex-S consists of a novel 17-plex and the previous 24-plex HIrisPlex assay

- In forensic validation testing, the 17-plex performed similarly to the 24-plex assay

- HIrisPlex-S consists of three prediction models for eye, hair, and skin colour

- https://hirisplex.erasmusmc.nl/_provides eye, hair, skin colour probabilities from genotypes

\begin{abstract}
Forensic DNA Phenotyping (FDP), i.e. the prediction of human externally visible traits from DNA, has become a fast growing subfield within forensic genetics due to the intelligence information it can provide from DNA traces. FDP outcomes can help focus police investigations in search of unknown perpetrators, who are generally unidentifiable with standard DNA profiling. Therefore, we previously developed and forensically validated the IrisPlex DNA test system for eye colour prediction and the HIrisPlex system for combined eye and hair colour prediction from DNA traces. Here we introduce and forensically validate the HIrisPlex-S DNA test system (S for skin) for the simultaneous prediction of eye, hair, and skin colour from trace DNA. This FDP system consists of two SNaPshot-based multiplex assays targeting a total of 41 SNPs via a novel multiplex assay for 17 skin colour predictive SNPs and the previous HIrisPlex assay for 24 eye and hair colour predictive SNPs, 19 of which also contribute to skin colour prediction. The HIrisPlex-S system further comprises three statistical prediction models, the previously developed IrisPlex model for eye colour prediction based on 6 SNPs, the previous HIrisPlex model for hair colour prediction based on 22 SNPs, and the recently introduced HIrisPlex-S model for skin colour prediction based on 36 SNPs. In the forensic developmental validation testing, the novel 17-plex assay performed in full agreement with the Scientific Working Group on DNA Analysis Methods (SWGDAM) guidelines, as previously shown for the 24-plex assay. Sensitivity testing of the 17-plex assay revealed complete SNP profiles from as little as $63 \mathrm{pg}$ of input DNA, equalling the previously demonstrated sensitivity threshold
\end{abstract}


of the 24-plex HIrisPlex assay. Testing of simulated forensic casework samples such as blood, semen, saliva stains, of inhibited DNA samples, of low quantity touch (trace) DNA samples, and of artificially degraded DNA samples as well as concordance testing, demonstrated the robustness, efficiency, and forensic suitability of the new 17-plex assay, as previously shown for the 24-plex assay. Finally, we provide an update of the publically available HIrisPlex website https://hirisplex.erasmusmc.nl/, now allowing the estimation of individual probabilities for 3 eye, 4 hair, and 5 skin colour categories from HIrisPlex-S input genotypes. The HIrisPlex-S DNA test represents the first forensically validated tool for skin colour prediction, and reflects the first forensically validated tool for simultaneous eye, hair and skin colour prediction from DNA.

Keywords: HIrisPlex-S; eye colour; hair colour; skin colour; Forensic DNA phenotyping; forensic developmental validation, predictive DNA analysis 


\section{Introduction}

When standard forensic DNA analysis based on short tandem repeats (STRs), or other types of polymorphic DNA markers such as single nucleotide polymorphisms (SNPs), fails to identify the donor of a human biological trace found at a crime-scene via comparative DNA profiling, i.e. no match with any known suspect or DNA database hit is obtained, alternative approaches are needed. Such DNA-based investigative intelligence can aid police by providing physical appearance information of the unknown trace donor from evidence DNA, which may help locating unknown perpetrators by allowing focused police investigation. Forensic DNA Phenotyping (FDP), used as a collective term for such DNA intelligence approaches, includes the prediction of externally visible characteristics (EVC's) from forensic DNA traces [1-3]. In its wider context, FDP additionally comprises the genetic inference of biogeographic ancestry and the estimation of epigenetic age from DNA. FDP is also useful for describing a person's physical appearance from skeletal remains using DNA [4-6], such as those that deal with missing person cases or mass disaster victim identification (DVI) scenarios, especially in cases where antemortem samples and known relatives are unavailable in the early phase of investigation. The latter is additionally relevant outside the forensic realm in fields such as anthropology and evolutionary biology, to reconstruct physical appearance information for the remains of persons from the recent or distant past, including the field of palaeogenetics $[4,6,7]$.

Over the last 10 years, candidate gene association studies and genome-wide association studies (GWASs), as well as subsequent prediction analyses, have established various EVC-predictive SNPs and prediction models, most notably for human pigmentation traits [8-30]. In particular, the prediction of broad (i.e., categorical) eye and hair colour phenotypes from SNP genotypes is now achievable with practically useful accuracies, for instance by applying the IrisPlex and HIrisPlex DNA test systems that have been forensically validated [31-34], as well as tested and applied [35, 36]. Similar tools for eye and hair colour DNA prediction that largely overlap in SNP predictors with the Iris/HIrisPlex systems have also been generated and used [21, 37-42]. This advancement in understanding the genetic basis and DNAbased predictability of eye and hair colour was achievable in part because these two pigmentation traits 
evolved in genetically homogeneous Europeans that were used in these genetic studies, and therefore are found today almost exclusively in people of (at least partial) European bio-geographic ancestry. In general, the success of genetic association studies depend on the genetic homogeneity of the study population used, such as people from 'within' continental regions. However, with its global variation maximized between continental groups, this is largely different for skin colour. Thus, genetic association studies on skin colour, either genome-wide or candidate gene focused studies could only be performed within continental groups such as Europeans and South Asians [10, 12, 14, 17, 26, 27, 30, 43] In consequence, the delivered genetic knowledge is less complete than that achievable for eye and hair colour.

Therefore, the predictability of skin colour from DNA [37-39] lagged behind that of eye and hair colour [30-42]. Valenzuela et al. [21] obtained a low $\mathrm{R}^{2}$ value for skin reflectance of $45.7 \%$ based on three SNPs. Spichenok et al. [38] applied 7 SNPs for predicting not-white, not-dark and not-white / notdark skin colour. However, the general limitation of using no-colour categories when attempting to predict colour, the authors were unable to obtain prediction outcomes in $28 \%$ of their samples [38], which could not be improved considerably in a subsequent study [37]. Pospiech et al.[44] used 17-18 SNPs and achieved a prediction accuracy expressed as area under the receiver operating characteristics curve (AUC) of 0.67 for light versus dark skin colour (AUC of 0.5 represents random prediction and 1.0 completely accurate prediction). Liu et al. [26] presented 9 SNPs suitable for predicting skin colour variation in Europeans and people from nearby regions, but not in Asians, Native Americans and Subs-Saharan Africans, which is explained by their identification via GWAS in Europeans. In 2014, Maronas et al. [25] published the first comprehensive study investigating the skin colour predictive value of 59 candidate pigmentation SNPs using three skin colour categories; white, intermediate and black. In this study, a subset of 10 of the most skin colour predictive SNPs from 8 genes was highlighted and high AUC values of 0.999 for White, 0.996 for Black and 0.803 for Intermediate skin colour were reported [25]. However, general problems of all of these previous skin colour prediction studies are the rather small sample size used, leading to limited reliability of the reported prediction accuracy estimates. 
Aiming to improve the reliability of skin colour prediction by using an increased number of global individuals as well as the level of detail of DNA-based skin colour prediction by increasing the number of predicted categories, we recently assessed 77 pigmentation SNPs from 37 genetic loci in 2025 globally dispersed human individuals [29]. From this dataset, we developed a novel prediction model for 5 skin colour categories based on 36 SNPs from 16 genes, which achieved AUC values of 0.75 for Very Pale, 0.73 for Pale, 0.75 for Intermediate, 0.84 for Dark, and 0.98 for Dark-Black skin colour [29]. As shown previously via direct comparison in 194 individuals from 17 different populations not involved in prediction model training or assessment [29], this new model outperformed the previously proposed model [25].

With the present study, we provide the necessary genotyping and phenotype prediction tools needed for implementing the recently established skin colour predictive DNA markers and prediction model [29] into Forensic DNA Phenotyping practice and other applications. We combined skin colour prediction from DNA with the previously established eye and hair colour prediction tools [31-34] into a single DNA test system, the HIrisPlex-S (S for skin) system. For this, we developed a novel multiplex genotyping assay for 17 skin colour prediction SNPs and performed forensic developmental validation according to the SWGDAM guidelines [45], as we previously did for the HIrisPlex assay, which targets 24 eye and hair colour predicting SNPs [34] of which 19 also contribute to skin colour prediction. Besides these two multiplex genotyping assays, the HIrisPlex-S system additionally consists of three statistical prediction models, the previous IrisPlex model for eye colour prediction [19, 31, 32, 34], the previous HIrisPlex model for hair colour prediction [33, 34], and the recently established HIrisPlex-S model for skin colour prediction [29]. Finally, we provide an easy-to-use web interface at https://hirisplex.erasmusmc.nl/ allowing the retrieval of individual prediction probabilities for 3 eye colour, 4 hair colour, and now 5 skin colour categories from HIrisPlex-S genotype input data of 41 SNPs. 


\section{Materials and methods}

A selection of body fluid and tissue samples were collected in-house from individuals with informed consent including single and multiple source samples and simulated casework samples (saliva, blood, semen, vaginal swabs and touched items). DNA was extracted from all the samples using the QIAamp DNA Mini kit (Qiagen, Hagen, Germany) according to the manufacturer's guidelines, or an in-house standard salting out protocol (unpublished). All the extracted DNA samples were quantified using the Quantifiler Human DNA Quantification kit (Applied Biosystems Inc., Foster City, USA) following the manufacturer's guidelines.

\section{Multiplex design and genotyping protocol}

A set of 36 SNPs from 16 genes were chosen as the final set of SNP predictors for skin colour based on our recent work published elsewhere [29], which include 19 of the 24 of the SNPs included in the previously developed HIrisPlex assay $[33,34]$ that we left unchanged in the design of the HIrisPlex-S system. The newly developed second genotyping assay of the HIrisPlex-S system includes 17 SNPs from 7 genes: ANKRD11 rs3114908, OCA2 rs1800414, BNC2 rs10756819, HERC2 rs2238289, SLC24A4 rs17128291, HERC2 rs6497292, HERC2 rs1129038, HERC2 rs1667394, TYR rs1126809, OCA2 rs1470608, SLC24A5 rs1426654, ASIP rs6119471, OCA2 rs1545397, RALY rs6059655, OCA2 rs12441727, $M C 1 R$ rs3212355, and DEF8 rs8051733. Primer3Plus, a publically available web-based design software, was used to design the 17 primer pairs and their respective single base extension (SBE) primers, using the default parameters of the software program [46]. For each SNP, both forward and reverse SBE primers were designed and tested, and the most suitable of the two was finally included in the multiplex system. To ensure complete capillary electrophoresis separation between the $17 \mathrm{SBE}$ products, poly-T tails of differing lengths were added to the 5' end of the SBE primers (Table 1). In order to cater for degraded samples, the PCR fragments were designed to be short as much possible and PCR fragment sizes were limited to less than $150 \mathrm{bp}$ if possible (the largest fragment is $170 \mathrm{bp}$ ). Prior to lab testing, all the primer sequences were analysed using AutoDimer software program [47] to avoid primer- 
primer interactions. All the marker details, primer sequences and primer concentrations are provided in Table 1. PCR amplification of all 17 SNPs was performed in a single multiplex PCR assay in a total volume of $10 \mu$, containing PCR primers in specified concentrations, $1 \mu 1$ genomic DNA extract (varying concentrations), 1X PCR buffer (Applied Biosystems), $2.5 \mathrm{mM} \mathrm{MgCl}_{2}$ (Applied Biosystems), $220 \mu \mathrm{M}$ of each dNTP (Roche, Mannheim, Germany) and 1.75 U AmpliTaq Gold DNA polymerase (Applied Biosystems). A GeneAmp PCR System thermocycler (Applied Biosystems) was used for all amplifications, with the following parameters: $95^{\circ} \mathrm{C}$ for 10 minutes, 33 cycles of $95^{\circ} \mathrm{C}$ for 30 seconds and $62^{\circ} \mathrm{C}$ for 30 seconds, $62^{\circ} \mathrm{C}$ for 5 minutes. The amplified PCR products were purified with ExoProStar $-\mathrm{S}$ (GE Healthcare Europe GmbH, Eindhoven, The Netherlands) and incubated at $37^{\circ} \mathrm{C}$ for 45 minutes and $80^{\circ} \mathrm{C}$ for 15 minutes. SBE was carried out for all 17 PCR products simultaneously in a single multiplex reaction using $2 \mu \mathrm{l}$ of the purified PCR product and $1 \mu \mathrm{l}$ of the SNaPshot Ready Reaction Mix with the following thermocycler parameters: $96^{\circ} \mathrm{C}$ for 2 minutes; 25 cycles of $96^{\circ} \mathrm{C}$ for 10 seconds, $50^{\circ} \mathrm{C}$ for 5 seconds, $60^{\circ} \mathrm{C}$ for 30 seconds. The extended products were then purified using $1 \mu$ of shrimp alkaline phosphatase (SAP) (USB Corporation) and incubated at $37^{\circ} \mathrm{C}$ for 45 minutes and $75^{\circ} \mathrm{C}$ for 15 minutes. Finally, the purified SBE products were analysed on the ABI 3130xl Genetic Analyser (Applied Biosystems) with POP-7 polymer on a $36 \mathrm{~cm}$ capillary length under an injection voltage of $2.5 \mathrm{kV}$ for 10 seconds and with a running time of 500 seconds at $60^{\circ} \mathrm{C}$. Gene Mapper v3.7 software program (Applied Biosystems) was used for the allele calling and analysis of the results.

\section{Sensitivity testing and optimization for peak height balance}

The sensitivity of the new 17-plex assay was evaluated to determine the minimum concentration of input DNA needed to achieve complete SNP profiles. For this, DNA from three individuals were diluted and quantified in duplicate with the Quantifiler Human DNA Quantification kit (Applied Biosystems) following the manufacturer's guidelines at $500 \mathrm{pg}, 250 \mathrm{pg}, 125 \mathrm{pg}, 63 \mathrm{pg}$ and $32 \mathrm{pg}$, and finally genotyped. A threshold of 50 relative fluorescence units (RFU) was used to call the allele peaks. In addition, an assessment of homozygote and heterozygote average peak heights of the 17-plex from 20 
replicates at $250 \mathrm{pg}$ DNA input using 10 different individuals was performed and standard errors of the means were calculated.

\section{Mixture studies and reproducibility testing}

DNA samples from two individuals of known genotype at genomic DNA concentration of $500 \mathrm{pg}$ were mixed in the ratios of 1:1, 1:5 and 1:10. DNA mixtures were used to assess the ability of the novel 17plex to detect DNA mixtures. Reproducibility or concordance testing was performed on 30 samples of varying DNA concentrations, SNP genotypes, and eye, hair, and skin colour phenotypes by five independent laboratories, four of which had no previous experience with the HIrisPlex-S assay. The five laboratories involved in the concordance testing were i) the Forensic Laboratory for DNA Research (FLDO) at the Leiden University Medical Centre (LUMC), ii) the research group of the Division Biological Traces at the Netherlands Forensic Institute (NFI), iii) the Malopolska Centre of Biotechnology of the Jagiellonian University in Poland, iv) the Department of Biology at the Indiana University Purdue University Indianapolis (IUPUI) in the USA, and v) the Department of Genetic Identification at Erasmus MC University Medical Center Rotterdam in the Netherlands. The latter laboratory who developed the assay with equal input from IUPUI, provided the other four laboratories with DNA samples, reagents, a written protocol, genotypes of the HIrisPlex assay, and an Excel macro for the statistical prediction of eye, hair and skin colour. Depending on the laboratory, SBE fragments were separated and genotyped on an ABI 3100 machine using POP-4, and an ABI 3130xl (or ABI 3500) machine using POP-7 polymer. Results were analysed using GeneMarker (Soft Genetics) or GeneMapper v4.0 (Applied Biosystems) software.

\section{Species specificity, stability testing and simulated case sample analysis}

The species origin of samples collected at a crime-scene often is unknown and they may represent contamination from different biological sources. Hence, a variety of non-human species was genotyped with the novel 17-plex assay to assess its human amplification specificity. Commercially available DNA 
samples of chicken, cat, mouse, pig, bovine, rat, and dog DNA at 3 ng input and a chimpanzee sample of $1 \mathrm{ng}$ input were used. DNA was obtained commercially from Novagen, Inc. (Madison, WI) for all but the chimpanzee sample, which was described elsewhere [48]. Human biological material collected at the crime scene can contain degraded DNA. To test for the influence of degraded DNA on the performance of the novel 17-plex, DNA from an individual with a concentration of $250 \mathrm{pg}$ was exposed to ultraviolet light at intervals of 0 seconds, 30 seconds, 60 seconds, 5 minutes, 10 minutes, 15 minutes, 20 minutes and 30 minutes using a Bio-Link (Vilber Lourmat) at a strength of $50 \mathrm{~J} / \mathrm{cm} 2$ and genotyped. We genotyped simulated casework samples that included fresh blood, dried blood, semen, vaginal swab, saliva, nasal mucus, samples with PCR inhibitor haematin, DNA mixtures and trace DNA of low quality and quantity with the novel 17-plex assay as well as the 24-plex HIrisPlex assay and under a blind proficiency testing conditions (Supplementary Table 2). All these samples were PCR-quantified using the Quantifiler Human DNA Quantification kit (Applied Biosystems) as per the manufacturer's guidelines.

\section{Population studies}

The novel 17-plex assay was used to genotype the HGDP-CEPH H952 [49] sample set from 51 global populations after removal of sample duplications and related samples. Due to DNA shortage, 762 HGDPCEPH individuals were finally used for skin colour prediction using the recently established prediction model [29] in combination with the genotypes from the 24-plex HIrisPlex assay established previously for these samples [33]. The MapViewer 7 (Golden Software, Inc., Golden, CO, USA) package was used to plot the genotype distributions of the 17 SNPs on the world map, respectively. In addition, we used these HGDP-CEPH genotype data to generate a global skin colour prediction map available with the HIrisPlex-S DNA test system. In order to fill in geographic gaps for global skin colour prediction using the HirisPlex-S model and the HGDP-CEPH set described above, 36 skin colour specific SNPs were 
downloaded from 777 individuals from 8 populations (IBS, FIN, ACB, CLM, GBR, KHV, PEL, PUR) of the 1000 genomes project [50] and included in the global skin colour prediction map.

\section{Categorical pigmentation prediction models}

The human skin colour prediction model used here has been recently described elsewhere [29]. Briefly, the skin colour categories as part of this prediction model are based on a dermatological established Fitzpatrick scale for skin colour and sun sensitivity. A dermatologist reviewed skin colour imagery and a questionnaire about the participants ability to tan, this led to the definition of a Fitzpatrick scale assignment, which was then converted to a specific skin colour category for this skin colour prediction model as follows: Fitzpatrick Scale I=Very Pale skin colour, II=Pale, combined III \& IV = Intermediate, V=Dark, VI=Dark to Black. This skin colour model completes the HIrisPlex-S system, which is now capable of predicting eye colour using the IrisPlex model coefficients [19, 31, 32, 34], hair colour using the HIrisPlex model coefficients [33, 34] and skin colour using the HIrisPlex-S model coefficients [29]. This skin colour prediction tool, together with the previously released eye and hair colour prediction tools, are made publicly available via an easy-to-use web interface at https://hirisplex.erasmusmc.nl/. Moreover, , there have been additions in the numbers of individuals used in the eye and hair colour prediction models with this publication, which explains potential slight differences in the eye and hair colour probabilities outputs relative to the previously enhanced eye and hair colour prediction models available via the HIrisPlex website as previously described by Walsh et al. [34]. In particular, 278 individuals for eye colour and 277 for hair colour were additionally included from a US-based population set containing individuals whose parental place of birth was outside the US in the following countries (Nigeria, Mexico, Columbia, India, Bangladesh, Palestine, Canada, China, Honduras, Germany, Philippines, Russia, Sudan, Japan, Saudi Arabia, Pakistan, El Salvador, Spain, Haiti, South Korea, Vietnam). These individuals are also included in the skin colour prediction model. Thus, as of August 2017, the model validation datasets underlying the individual probabilities available from this website consists of 9466 individuals for eye colour, 1878 individuals for hair colour, and 1423 individuals for skin 
colour. When the model input alleles are generated from the two multiplex genotyping assays and entered into the HIrisPlex-S prediction tool, individual probabilities for 3 eye colour, 4 hair colour, and 5 skin colour categories are generated from the underlying eye, hair, and skin colour prediction models, respectively. Interpretation rules for eye colour based on the category with the highest probability value as well as hair colour based on a prediction guide have been previously published [31-34], while the interpretation of skin colour is described here (see below).

\section{Results and Discussion}

Multiplex design, sensitivity testing and peak height balance studies

As presented here, the HIrisPlex-S system includes two genotyping assays based on the principle of multiplex PCR followed by multiplex single-base primer extension (SBE) using SNaPshot chemistry: a novel 17-plex assay described here and the previously developed and described 24-plex HIrisPlex assay $[33,34]$ that remained unchanged in the HIrisPlex-S system. All together the two multiplex assays target

41 eye and/or hair and/or skin colour-predicting SNPs. For skin colour prediction on a 5-category level (Very Pale, Pale, Intermediate, Dark and Dark-Black), the HIrisPlex-S system considers all 36 SNPs recently highlighted as suitable predictors of categorical skin colour [29], of which 19 overlap with those targeted with the 24-plex HIrisPlex assay: $M C 1 R$ rs 1805007, MC1R rs1805008, MC1R rs11547464, $M C 1 R$ rs885479, MC1R rs228479, MC1R rs1805006, MC1R rs1110400, IRF4 rs12203592, OCA2 rs1800407, SLC45A2 rs16891982, SLC45A2 rs28777, HERC2 rs12913832, TYR rs1042602, TYR rs1393350, PIGU rs2378249, LOC105370627 (formerly SLC24A4) rs12896399, SLC24A4 rs2402130, TYRP1 rs683, and KITLG rs12821256. The remaining 17 SNPs targeted with the newly developed second multiplex assay are ANKRD11 rs3114908, BNC2 rs10756819, SLC24A4 rs17128291, HERC2 rs2238289, HERC2 rs6497292, HERC2 rs1129038, HERC2 rs1667394, TYR rs1126809, OCA2 rs1470608, OCA2 rs1800414, OCA2 rs12441727, OCA2 rs1545397, SLC24A5 rs1426654, ASIP rs6119471, RALY rs6059655, MC1R rs3212355, and DEF8 rs8051733. 
PCR amplicon size of approximately $170 \mathrm{bp}$ or less (ideally $150 \mathrm{bp}$ ) were achieved for almost all of the SNPs in the novel 17-SNP assay (Table 1), akin to those in the previous 24-plex HIrisPlex assay [34], allowing application to degraded DNA typically found in forensic samples. Both the PCR, and SBE multiplexes were optimized to achieve the optimal balanced 17-SNP genotype profile, to ensure accurate results being obtained across all the SNPs in a wide range of samples with different DNA quantities and qualities. Despite these efforts, the peak height of one SNP (ASIP rs6059655) was lower compared to the other 16 SNPs in this multiplex assay, which makes this DNA marker a candidate for dropout in case of low quantity or quality DNA being analysed. It is workable, however, in cases where allelic dropouts are suspected in a DNA sample analysed, that this SNP is genotyped by singleplex PCR/SBE.

To test for the sensitivity of the novel 17-plex assay, DNA samples from three individuals with different skin colour categories, hence different SNP alleles, were serially diluted and PCR-quantified input DNA amounts of $500 \mathrm{pg}, 250 \mathrm{pg}, 125 \mathrm{pg}, 63 \mathrm{pg}$ and $32 \mathrm{pg}$ were genotyped. Individual 1 displayed phenotypic dark skin colour, individual 2 displayed phenotypic intermediate skin colour, and individual 3 displayed phenotypic pale skin colour. As seen in Figure 1, it was possible to obtain full 17-SNP profiles down to 63 pg input DNA, while with 32 pg locus or allele drop-outs were seen in all three individuals tested. In particular, individual 1 showed locus or allele dropouts at 6 SNPs: ANKRD11 rs3114908 (allele T from the heterozygous CT), BNC2 rs10756819 (allele G from the heterozygous GA), HERC2 rs6497292 (heterozygous CT), HERC2 rs1667394 (allele C of heterozygous CT), OCA2 rs1470608 (heterozygous CA) and $R A L Y$ rs6059655 (homozygous genotype CC). Individual 2 presents dropouts at 5 SNPs BNC2 rs10756819 (allele G of heterozygous GA), OCA2 rs1470608 (heterozygous genotype CA), SLC24A5 rs1426654 (homozygous AA), OCA2 rs12441727 (heterozygous genotype GA), and DEF8 rs8051733 (heterozygous genotype CT). Individual 3 reflects dropouts at 3 SNPs: HERC2 rs 1129038 (homozygous AA), TYR rs1126809 (allele A of heterozygous genotype GA), and RALY rs6059655 (homozygous CC). As expected, with a decrease in starting DNA amount, increased heterozygote peak imbalance was observed. Notably, the sensitivity threshold of the novel 17-plex assay obtained at 63 pg input DNA equals that of the 24-plex HIrisPlex assay as established previously [34]. 
An important aspect in assay design is to assess balance between the peak heights (RFUs) of homozygote and heterozygote alleles. Figure 2 illustrates the average peak height ranges observed in homozygote and heterozygote genotypes at $250 \mathrm{pg}$ of input DNA across 10 different individuals of various skin colours and thus different SNP alleles from 20 replicate analyses for each individual DNA samples $\left(\mathrm{N}_{\text {total }}=200\right.$ profiles). As evident, we obtained reasonably good balance (peak heights are similar or within $10 \%$ of each other) of the homozygote stages of both alleles for most of the 17 SNPs (Figure 2A) with the exception of four SNPs i.e., OCA2 rs18004141, HERC2 rs6497292, OCA2 rs1545397, and OCA2 rs12441727. For 5 SNPs, it was not possible to display the average peak heights for the T/T homozygote allele of $A N K R D 11$ rs3114908 and $R A L Y$ rs6059655, respectively, the C/C homozygote allele of SLC24A4 rs17128291 and ASIP rs6119471, respectively, as well as the A/A homozygote allele of $T Y R$ rs1126809 and MC1R rs3212355, respectively, because these homozygote genotypes were not represented in the test set used (consequently these alleles are absent from Figure 2A). We also observed good peak height balance for the heterozygote allele stages for most of these 17 SNPs, with the exception of BNC2 rs10756819, TYR 1126809, and OCA2 rs12441727 (Figure 2B). For two SNPs, i.e., OCA2 rs1800414 and MC1R rs3212355 the heterozygote genotypes were absent from the test set used here (and are therefore absent from Figure 2B). We expect that at least some of the allelic peak height imbalances seen are influenced by differences in intensity levels of the four fluorescence dyes used to label the four bases in the primer extension reaction of the $\mathrm{SNaPshot}$ chemistry, which cannot be avoidable unless moving away from fluorescence-based SNP-typing technologies. In the near future, it is believed that targeted massively parallel sequencing (MPS) designs [51] will start to replace single base extension assays using the SNaPshot chemistry; however this will mean that all forensic laboratories would require a bench-top sequencer, which may take some years to occur. For the results on the developmental validation of the 24-plex HIrisPlex assay, see Walsh et al. [34].

\section{DNA mixture studies}


DNA from two individuals carrying different pigmentation phenotypes and thus different SNP genotypes, at a DNA input level of $500 \mathrm{pg}$ were mixed in the ratios of 1:1, 1:5 and 1:10 and genotyped with the 17plex (for respective results of the HIrisPlex assay, see [34]). Individual 1 reported a phenotype of brown eye, black hair and dark skin colour, while individual 2 reported blue eyes, blond hair and pale skin colour. These two individuals differ at 6 of the 17 SNPs, for 5 of them this refers to heterozygote in one and homozygote in the other samples, while for one SNP the two alleles are seen in opposite homozygote states in these two individuals (Figure 3). In the 1:1 mixture, there appears to be peak balance (no obvious allelic height discrepancies, similar in peak height) in several of the 17 SNPs except at HERC2 rs1129038 (SNP7 in Figure 3 when counting from the left), HERC2 rs1667394 (SNP8), OCA2 rs1545397 (SNP 13) and DEF8 rs8051733 (SNP17). Nevertheless, it is difficult to deduce if the profile at a mixture ratio of 1:1 is a true mixture, or a single source sample with heterozygous alleles. However, at mixture ratios of 1:5, and more so at 1:10, dropouts and peak imbalances increased at BNC2 rs10756819 (SNP 3), HERC2 rs2238289 (SNP4) and HERC2 rs6497292 (SNP6), HERC2 rs1129038 (SNP7), HERC2 rs1667394 (SNP8) and OCA2 rs1545397 (SNP13). In general, peak height imbalance could indicate a probable presence of mixtures, however, a dropout may not be considered true unless it was compared to a single sample profile. Moreover, as with eye and hair colour and using the Iris/HIrisPlex system, also for skin colour using the HIrisPlex-S system, there is a considerable chance that individuals who contribute to a DNA mixture have overlapping SNP alleles, especially if they share the same pigmentation phenotypes, which makes DNA mixtures difficult if not impossible to detect from such data. This, however, reflects the general disadvantage in mixture deconvolution when using autosomal SNPs, and is not a specific problem of SNP assays of the Iris/HIris/HIrisPlex-S systems. It is to be noted, however, that in routine forensic casework, STR profiling is typically performed prior to FDP analysis and allows detecting if a DNA mixture is present or not. STR profiling currently is the method of choice for mixture detection and deconvolution [52], and can be improved when massively parallel sequencing technologies are applied for STR analysis. 


\section{Reproducibility studies}

Concordance testing is required to assess the implementation of a new genotyping assay in a laboratory, and is particularly informative when involving those without previous experience with the assay being tested. Apart from the laboratories at Erasmus MC and IUPUI involved in developing the novel 17-plex, the other 3 laboratories included in this concordance testing had no previous experience with this genotyping assay at the time. However, all laboratories had previous experience with the 24-plex HIrisPlex assay. Only the novel 17-plex assay was tested in this concordance study, as the HIrisPlex assay had already been forensically validated before, including concordance testing [34].

Of the total of 30 DNA samples with varying DNA concentrations distributed for concordance testing (see Supplementary Table 1), 25 (83.3\%) were genotyped correctly at all 17 SNPs. Of the 5 samples for which discordant genotypes were observed, 4 samples had genotyping errors at 1 or 2 SNPs, respectively. One sample had dropouts or errors in 4 of the 5 laboratories involved (Supplementary Table 1). However; with $48 \mathrm{pg}$, this sample had the lowest input DNA amount of all 30 samples used in the concordance testing, and was the only one in this sample set that was below the established sensitivity threshold of $63 \mathrm{pg}$ (see above), which explains the insufficient results. Lab 3 produced erroneous results in 4 samples, lab 2 in two samples, and lab 4 as well as lab 5 in one sample, respectively.

To test for concordance not only regarding genotype generation but also phenotype prediction, the 24-plex HIrisPlex genotypes were provided to the participating laboratories, as was access to the eye, hair, and skin colour prediction models for probability estimation. Eye, hair, and skin colour prediction probabilities were established correctly in 28 of the 30 samples (93.3\%) by all the labs. Lab 3 could not establish the correct prediction probabilities in sample $5(110 \mathrm{pg})$, and 4 laboratories had issues with determining the pigmentation phenotypes of sample 26, which was the one with the lowest DNA input of $48 \mathrm{pg}$ and was below the established sensitivity threshold (Supplementary Table 1). In such circumstances, reporting of the predictions generated from low input DNA typing (below the set threshold, in this case $63 \mathrm{pg}$ ), should include a clause that the prediction will be impacted by possible missing alleles due to potential allelic drop/out. 


\section{Specificity studies}

A variety of animal species were tested with the novel 17-plex assay to assess its human specificity, as done previously for the 24-plex HIrisPlex assay [34]. Supplementary Figure 1 depicts the peaks observed above the 50 relative fluorescent units threshold in each of the non-human species at $3 \mathrm{ng}$ and for the chimpanzee sample at $1 \mathrm{ng}$. Not unexpected given the evolutionary relationship between chimpanzees and humans, 14 out of 17 SNPs revealed allelic signals in the chimp sample. In contrast, almost no peaks were called in all other, evolutionary more distant species tested such as dog, cat, rat, mouse, pig, bovine and chicken. The only exceptions were one peak called in chicken and one in bovine (plus off-size peaks that were therefore not called: 1 in chicken, 1 in rat, and 2 in dogs, see Supplementary Figure 1). Therefore, with the exception of closely related non-human primates, this study provides good evidence for the human specificity of genotypes obtained with the novel 17-plex assay. However, it should be kept in mind that FDP is typically performed subsequent to standard DNA profiling and observing forensic STR profiles provides sufficiently reliable evidence on the human source of the DNA used.

\section{Degradation and simulated casework studies}

In order to test the ability of the 17-plex assay to deal with degraded DNA, that is often confronted with in forensic DNA analysis, aliquots of the same single source DNA sample at an input of $250 \mathrm{pg}$ was subjected to artificial degradation by exposing to ultraviolet light at varying time intervals of 0 seconds, 30 seconds, 1 minute, 5 minutes, 10 minutes, 20 minutes, and 30 minutes. These DNA samples were then genotyped with the novel 17-plex assay. Full 17-SNP profiles were obtained from all degraded DNA samples receiving ultraviolet light exposure for up to 10 minutes. After 20 minutes of UV light exposure, allele dropouts were observed at two SNPs, OCA2 rs1470608 and BNC2 rs10756819. These results indicate the robustness of the assay to deal with DNA degradation, at least to the level generated with these experiments, where larger fragments (such as those used in commercial STR kits) would more than likely drop out. 
To test for the ability of the complete HIrisPlex-S system to produce reliable genotypes as well as reliably predicted pigmentation phenotypes from different forensically relevant biological materials, 25 simulated casework samples from blood, semen, saliva, touch DNA, mixtures as well as high and low concentrations of haematin inhibited samples were genotyped with both multiplex assays; the novel 17plex assay and the 24-plex HIrisPlex assay. All these samples were blind-tested and the details are presented in Supplementary Table 2. Of the 19 single source samples used here, 17 (90\%) were correctly genotyped and correctly phenotyped for all three pigmentation traits, even though several included low peak heights due to low amounts of input DNA, and two specifically below the established sensitivity threshold of $63 \mathrm{pg}$. The two single source samples where no genotypes and thus no phenotypes could not be established represent a (touch) DNA sample and a strongly inhibited sample containing high concentrations of haematin, which both showed many allelic dropouts. Of the 6 mixture samples, five were correctly identified as DNA mixtures due to noticeable peak imbalance; however, phenotype prediction was not possible in these samples because of impossible mixture deconvolution. The one mixture sample not correctly identified as DNA mixture was a low quantity touch DNA sample from multiple sources; because it was incorrectly interpreted as a single source, the phenotype interpretation was incorrect too. Thus, the HIrisPlex-S system was effective in producing reliable results across different mock samples representing different casework type scenarios with varying input concentrations, particularly for single source samples.

\section{Population studies, global SNP distributions and global skin colour prediction}

The novel 17-plex assay was applied to the HGDP-CEPH H952 sample set ( $\mathrm{n}=952$ ) by excluding 190 individuals due to DNA shortage, leaving 762 individuals in the analysis. Each of the 17 SNP's global allelic frequency distribution is shown in Supplementary Figure 2, demonstrating various degrees of global variation. As may be expected for SNPs associated with and predictive for skin colour, a trait with strong continental differentiation, several of these 17 SNPs provide a relatively strong differentiation between different continental regions. Most evident were European versus Non-European differentiation 
for SLC24A5 rs1426654 (Supplementary Figure 2K) and HERC2 rs1129038 (Supplementary Figure 2G), Asian versus non-Asian differentiation for MC1R rs3212355 (Supplementary Figure 2P), OCA2 rs1545397 (Supplementary Figure 2M), and OCA2 rs1800414 (Supplementary Figure 2B); and African versus non-African differentiation for ASIP rs6119471 (Supplementary Figure 2L), HERC2 rs6497292 (Supplementary Figure 2F), HERC2 rs1667395 (Supplementary Figure 2H), OCA2 rs12441727 (Supplementary Figure 2O), and BNC2 rs10756819 (Supplementary Figure 2C). For information regarding continental differentiation of the 19 skin colour predicting SNPs that are part of the HIrisPlex assay (and thus not shown here), see supplementary figure S2-S4 of Walsh et al. [33].

Figure 4 depicts the prediction of the five skin-colour categories; Very Pale, Pale, Intermediate, Dark and Dark-Black on a global scale, as achieved with the HIrisPlex-S system using the results of the novel 17-plex genotyped generated here together with the previously generated 24-plex HIrisPlex genotypes [34], and applying the global skin colour prediction model published recently [29]. For this, we used the HGDP-CEPH set and 8 additional population samples from the 1000 Genomes Project [50] (IBS, FIN, ACB, CLM, GBR, KHV, PEL, PUR) selected to fill gaps in the global areas represented by the HGDP set as much as possible. In this analysis, no threshold parameters were used and the category with the highest probability value was used to conclude the predicted skin colour category for illustration purpose (but see the next section for more details). As evident from Figure 4, global skin colour prediction achieved with the HIrisPlex-S system agrees with the overall expectation of global skin colour distribution. Although skin colour phenotypes are not directly available for the individuals analysed, they can be broadly assumed from general knowledge of global skin colour distribution. For instance, SubSaharan Africans are known to typically have very dark skin colour, which is also the case for most (but not all) New Guineans. Indeed, we exclusively predicted Dark-Black in the HGDP-CEPH Sub-Saharan Africans, which is the darkest skin colour category in the prediction model, as well as in HGDP-CEPH New Guineans (except for a single individual predicted Dark). Europeans are known to have very pale, pale, and intermediate skin colour. Indeed, we predicted these 3 skin colour categories in the HGDPCEPH Europeans, in addition to Dark in Southern Europeans from Sardinia, which can be true. Very Pale 
is predicted rarely in these Europeans, which is explained by the limited number of North and NorthWestern populations used. Asians are known to vary highly in skin colour across the region with the exception of very pale skin; indeed, we predicted Pale, Intermediate, Dark, and Dark-Black skin colour in HGDP-CEPH East and South Asians. To note, the HGDP-CEPH samples from Senegal ( $\mathrm{n}=21)$, Nigeria $(n=21)$, Kenya $(n=11)$, and Papua New Guinea, $(n=17)$ were previously used in the development of the skin colour prediction model [29]; hence, predictions in these populations are not completely independent, as is true for all other population samples included here. In any case, additional population testing using global DNA samples for which skin colour phenotypic information is available is very likely to support the global prediction patterns presented here. Moreover, newly identified skin colour associated SNPs should also be assessed for their contribution to global skin colour prediction models in future studies, such as those recently identified by Tishkof et al. [53] and Martin et al. [54].

The prediction models for eye, hair, and skin colour of the HIrisPlex-S system

The addition of the recently established skin colour predictive SNPs and skin colour prediction model [29] to the previously established HIrisPlex system for eye and hair colour prediction [34], therefore now named HIrisPlex-S system, completes the categorical prediction of human pigmentation traits from DNA. Consequently, we have updated the publically available HIrisPlex website https://hirisplex.erasmusmc.nl/ now additionally providing access to the skin colour prediction model in addition to the eye and hair colour prediction models available previously. Thus, this website now provides individual probabilities for 3 eye colour, 4 hair colour, and 5 skin colour categories from HIrisPlex-S input genotypes of 41 SNPs. Note that in addition to adding skin colour prediction to the website, we also enhanced the eye and hair colour prediction models by including more individuals in the model-underlying reference datasets, respectively (see details provided in the Material and Methods section).

An illustrative example of the skin colour prediction results obtained with the HIrisPlex-S system is shown in Figure 5 for a subset of 35 individuals originating from 8 American, European, African and Asian countries (USA, Ireland, China, Mexico, Nigeria, Rwanda, India, El Salvador), Notably, these 
individuals were not previously used for building or validating the skin colour prediction model. In this

figure, the individual skin photographs were ordered according to the outcomes of the HIrisPlex-S system i.e., with increase in the highest prediction probabilities from the top left hand corner to the bottom right hand corner and in the skin colour direction of Very Pale to Dark-Black. Skin colour phenotypes were not considered in the ordering. As evident, there is a high correlation between the visual representation of the skin colour phenotypes in the skin photographs and the highest DNA-predicted skin colour category in these example individuals used for illustration purposes only.

\section{Skin colour prediction interpretation}

To acknowledge the complex nature of skin colour and its global variation predictable with the HIrisPlex-S system, we recommend that the final conclusion on the most likely skin colour from the HIrisPlex-S genotypes is obtained from the predicted skin colour category with the highest probability value with influence from the second highest probability value as generated by the HIrisPlex-S model. Depending on its strength, the second highest probability category can influence the detected skin colour together with the highest probability category. Two examples are shown in Figure 6, and also outlined in the tool manual available at https://hirisplex.erasmusmc.nl/. In example 1, although Pale is the predicted $\underline{\text { skin colour category with the highest probability in both of these individuals with almost identical }}$ probability values $(0.588$ and 0.582 , respectively), in A) the Very Pale category is second high $(0.389)$ whereas in B) it is the Intermediate category $(0.398)$ with very similar probabilities. From this one can conclude that individual A is unlikely to darken / tan with sun exposure in summer months, whereas individual B likely will. It can thus be expected individual B to have slightly darker skin colour at least after sun exposure than individual A, as visible from the photographs. Consequently, although both individuals have almost the same highest probability for Pale, the finally concluded skin colour prediction for individual B shall be Pale to Intermediate, whereas for individual A it is Pale to Very Pale. Likewise, individuals C and D have the very same high probability for Dark (0.693) as highest probability value, in $\underline{\mathrm{C} \text { the second highest probability }(0.299) \text { is for Intermediate whereas in D it is for Dark-Black (0.301) with }}$ 
almost the same value. Consequently, although both individuals have the same highest probability for Dark, the final skin colour conclusion for individual C shall be Dark to Intermediate, whereas for individual D it is Dark to Dark-to-Black. Further investigation into the precise threshold at which each $\underline{\text { category will impact on the major (highest) category prediction should be performed in more samples }}$ than available here. However, in Table 2 we provide a preliminary skin colour prediction guide with the current threshold levels. Lastly, as the topic of likelihood ratio (LR) versus probability with relation to the interpretation of Forensic DNA Phenotyping model outcomes has been debated, explanations on the preferred use of probabilities instead of likelihood ratios with regard to the DNA prediction of EVCs have been provided recently by Caliebe et al. [55]

\section{Conclusions}

We hereby introduce and forensically validate the HIrisPlex-S DNA test system capable of simultaneously predicting categorical eye, hair and skin colour phenotypes from DNA, which consists of two multiplex genotyping assays and three statistical prediction models for eye, hair and skin colour respectively. A novel multiplex assay targeting 17 skin colour predictive SNPs was developed and forensically validated as an addition to the previously developed and validated HIrisPlex assay targeting 24 eye and hair colour predictive SNPs, of which 19 are additionally used for skin colour prediction. The forensic developmental validation of the novel 17-plex system fulfils SWGDAM guidelines in terms of sensitivity, stability, mixtures and simulated casework sample studies [45] as previously shown for the 24-plex HIrisPlex assay [34]. Most notably, the HIrisPlex-S system is capable of generating full 41-SNP profiles from a minimum input DNA quantity of $63 \mathrm{pg}$, reflecting the sensitivity threshold for obtaining full profiles with both multiplex assays. The newly developed 17-plex assay is capable of coping with degraded DNA samples due to the PCR fragment sizes of less than $150 \mathrm{bp}$ and as proven experimentally in preliminary DNA degradation testing, and as was previously established also for the 24-plex HIrisPlex assay [34]. Finally, we updated the HIrisPlex website https://hirisplex.erasmusmc.nl/ by making available the skin colour model in addition to the eye and hair colour model available previously so that upload of 
genotypes from all 41 SNPs of the HIrisPlex-S system allows generating individual probabilities for 3 eye colour, 4 hair colour and 5 skin colour categories. Overall, the results of the forensic developmental validation performed here and previously [34] demonstrate the robustness and reliability of the HIrisPlexS genotyping assay and may encourage its use for the prediction of all three human pigmentation traits from DNA in criminal cases, missing person cases, and outside the forensic arena such as those in anthropological or evolutionary applications to bringing back eye, hair and skin colour of deceased persons from analysing their skeletal remains. In the future, the identification of additional skin colour DNA predictors and their addition to the DNA prediction system would be appreciated, particularly to improve the prediction accuracies of the three 'white' categories Very Pale, Pale, and Intermediate that with the current model are predicted with considerably lower accuracy than the Dark and Dark-Black skin colour categories [29]. Moreover, in the long run, a move towards a quantitative prediction output for skin colour, as well as for eye and hair colour, is the preferred direction of further research and development.

\section{Acknowledgements}

We are grateful to all volunteers who provided biological samples and pigmentation phenotype information to this study. MK, FL and LC are supported by Erasmus MC University Medical Center Rotterdam. The work of SW has funding support from the National Institute of Justice (Grant 2014-DNBX-K031) and Indiana University Purdue University Indianapolis (IUPUI). FL is additionally supported by the Thousand Talents Program for Distinguished Young Scholars China. WB, EP and MK-B are supported by the Jagiellonian University. EP is additionally supported by the Foundation for Polish Science programme START 2017. 


\section{References}

1. M. Kayser and P. Schneider, DNA-based prediction of human externally visible characteristics in forensics: motivations, scientific challenges, and ethical considerations. Foren Sci Int Genet, 2009. 3: p. 154 - 161.

2. M. Kayser and P. de Knijff, Improving human forensics through advances in genetics, genomics and molecular biology. Nat Rev Genet, 2011. 12(3): p. 179-192.

3. M. Kayser, Forensic DNA Phenotyping: Predicting human appearance from crime scene material for investigative purposes. Foren Sci Int Genet, 2015. 18(Supplement C): p. 33-48.

4. J. Draus-Barini, S. Walsh, E. Pospiech, T. Kupiec, H. Glab, W. Branicki, and M. Kayser, Bona fide colour: DNA prediction of human eye and hair colour from ancient and contemporary skeletal remains. Invest Genet, 2013. 4(1): p. 3.

5. L. Chaitanya, I.Z. Pajnic, S. Walsh, J. Balazic, T. Zupanc, and M. Kayser, Bringing colour back after 70 years: Predicting eye and hair colour from skeletal remains of World War II victims using the HIrisPlex system. Foren Sci Int Genet, 2016. 26: p. 48-57.

6. T.E. King, G.G. Fortes, P. Balaresque, M.G. Thomas, D. Balding, P.M. Delser, et al., Identification of the remains of King Richard III. Nat Commun, 2014. 5.

7. I. Olalde, M.E. Allentoft, F. Sanchez-Quinto, G. Santpere, C.W.K. Chiang, M. DeGiorgio, et al., Derived immune and ancestral pigmentation alleles in a 7,000-year-old Mesolithic European. Nature, 2014. 507(7491): p. 225-228.

8. P.A. Kanetsky, J. Swoyer, S. Panossian, R. Holmes, D. Guerry, and T.R. Rebbeck, A Polymorphism in the Agouti Signaling Protein Gene Is Associated with Human Pigmentation. Am J Hum Genet, 2002. 70(3): p. 770-775.

9. R.L. Lamason, M.-A.P.K. Mohideen, J.R. Mest, A.C. Wong, H.L. Norton, M.C. Aros, et al., SLC24A5, a Putative Cation Exchanger, Affects Pigmentation in Zebrafish and Humans. Science, 2005. 310(5755): p. 1782-1786.

10. R.P. Stokowski, P.V.K. Pant, T. Dadd, A. Fereday, D.A. Hinds, C. Jarman, et al., A Genomewide Association Study of Skin Pigmentation in a South Asian Population. Am J Hum Genet, 2007. 81(6): p. $1119-1132$.

11. D.L. Duffy, G.W. Montgomery, W. Chen, Z.Z. Zhao, L. Le, M.R. James, et al., A Three SingleNucleotide Polymorphism Haplotype in Intron 1 of OCA2 Explains Most Human Eye-Color Variation. Am J Hum Genet, 2007. 80(2): p. 241-252.

12. J. Graf, J. Voisey, I. Hughes, and A. van Daal, Promoter polymorphisms in the MATP (SLC45A2) gene are associated with normal human skin color variation. Hum Mutat, 2007. 28(7): p. 710-7.

13. R.A. Sturm, D.L. Duffy, Z.Z. Zhao, F.P. Leite, M.S. Stark, N.K. Hayward, et al., A single SNP in an evolutionary conserved region within intron 86 of the HERC2 gene determines human blue-brown eye color. Am J Hum Genet, 2008. 82(2): p. 424-31.

14. J. Han, P. Kraft, H. Nan, Q. Guo, C. Chen, A. Qureshi, et al., A Genome-Wide Association Study Identifies Novel Alleles Associated with Hair Color and Skin Pigmentation. PLoS Genet, 2008. 4(5): p. e1000074.

15. H. Eiberg, J. Troelsen, M. Nielsen, A. Mikkelsen, J. Mengel-From, K. Kjaer, and L. Hansen, Blue eye color in humans may be caused by a perfectly associated founder mutation in a regulatory element located within the HERC2 gene inhibiting OCA2 expression. Hum Genet, 2008. 123(2): p. 177-187.

16. M. Kayser, F. Liu, A. Janssens, F. Rivadeneira, O. Lao, K. van Duijn, et al., Three genome-wide association studies and a linkage analysis identify HERC2 as a human iris color gene. Am J Hum Genet, 2008. 82: p. 411 - 423. 
17. P. Sulem, D. Gudbjartsson, S. Stacey, A. Helgason, T. Rafnar, M. Jakobsdottir, et al., Two newly identified genetic determinants of pigmentation in Europeans. Nat Genet, 2008. 40: p. 835 - 837.

18. E.A. Grimes, P.J. Noake, L. Dixon, and A. Urquhart, Sequence polymorphism in the human melanocortin 1 receptor gene as an indicator of the red hair phenotype. Foren Sci Int, 2001. 122(2): p. 124-129.

19. F. Liu, K. van Duijn, J. Vingerling, A. Hofman, A. Uitterlinden, A. Janssens, and M. Kayser, Eye color and the prediction of complex phenotypes from genotypes. Curr Biol, 2009. 19: p. 192 - 193.

20. J. Mengel-From, T. Wong, N. Morling, J. Rees, and I. Jackson, Genetic determinants of hair and eye colours in the Scottish and Danish populations. BMC Genetics, 2009. 10(1): p. 88.

21. R.K. Valenzuela, M.S. Henderson, M.H. Walsh, N.A. Garrison, J.T. Kelch, O. Cohen-Barak, et al., Predicting Phenotype from Genotype: Normal Pigmentation*. J Foren Sci, 2010. 55(2): p. 315-322.

22. F. Liu, A. Wollstein, P.G. Hysi, G.A. Ankra-Badu, T.D. Spector, D. Park, et al., Digital Quantification of Human Eye Color Highlights Genetic Association of Three New Loci. PLoS Genet, 2010. 6(5): p. e1000934.

23. W. Branicki, F. Liu, K. van Duijn, J. Draus-Barini, E. Pospiech, S. Walsh, et al., Model-based prediction of human hair color using DNA variants. Hum Genet, 2011. 129: p. 443 - 454.

24. E.E. Quillen, M. Bauchet, A.W. Bigham, M.E. Delgado-Burbano, F.X. Faust, Y.C. Klimentidis, et al., OPRM1 and EGFR contribute to skin pigmentation differences between Indigenous Americans and Europeans. Hum Genet, 2012. 131(7): p. 1073-1080.

25. O. Maroñas, C. Phillips, J. Söchtig, A. Gomez-Tato, R. Cruz, J. Alvarez-Dios, et al., Development of a forensic skin colour predictive test. Foren Sci Int Genet, 2014. 13: p. 34-44.

26. F. Liu, M. Visser, D.L. Duffy, P.G. Hysi, L.C. Jacobs, O. Lao, et al., Genetics of skin color variation in Europeans: genome-wide association studies with functional follow-up. Hum Genet, 2015. 134(8): p. 823-35.

27. L.C. Jacobs, M.A. Hamer, D.A. Gunn, J. Deelen, J.S. Lall, D. van Heemst, et al., A Genome-Wide Association Study Identifies the Skin Color Genes IRF4, MC1R, ASIP, and BNC2 Influencing Facial Pigmented Spots. J Invest Dermatol, 2015. 135(7): p. 1735-42.

28. W. Branicki and M. Kayser, Prediction of Human Pigmentation Traits from DNA Polymorphisms, in eLS. 2015, John Wiley \& Sons, Ltd.

29. S. Walsh, L. Chaitanya, K. Breslin, C. Muralidharan, A. Bronikowska, E. Pospiech, et al., Global skin colour prediction from DNA. Hum Genet, 2017. 136(7): p. 847-863.

30. P. Sulem, D. Gudbjartsson, S. Stacey, A. Helgason, T. Rafnar, K. Magnusson, et al., Genetic determinants of hair, eye and skin pigmentation in Europeans. Nat Genet, 2007. 39: p. 1443 1452.

31. S. Walsh, F. Liu, K. Ballantyne, M. van Oven, O. Lao, and M. Kayser, IrisPlex: a sensitive DNA tool for accurate prediction of blue and brown eye colour in the absence of ancestry information. Foren Sci Int Genet, 2011. 5: p. 170 - 180.

32. S. Walsh, A. Lindenbergh, S. Zuniga, T. Sijen, P. de Knijff, M. Kayser, and K. Ballantyne, Developmental validation of the IrisPlex system: determination of blue and brown iris colour for forensic intelligence. Foren Sci Int Genet, 2011. 5: p. 464 - 471.

33. S. Walsh, F. Liu, A. Wollstein, L. Kovatsi, A. Ralf, A. Kosiniak-Kamysz, et al., The HIrisPlex system for simultaneous prediction of hair and eye colour from DNA. Foren Sci Int Genet, 2013. 7: p. 98 115.

34. S. Walsh, L. Chaitanya, L. Clarisse, L. Wirken, J. Draus-Barini, L. Kovatsi, et al., Developmental validation of the HIrisPlex system: DNA-based eye and hair colour prediction for forensic and anthropological usage. Foren Sci Int Genet, 2014. 9: p. 150-161.

35. V. Kastelic, E. Pośpiech, J. Draus-Barini, W. Branicki, and K. Drobnič, Prediction of eye color in the Slovenian population using the IrisPlex SNPs. Croat Med J, 2013. 54(4): p. 381-386. 
36. L. Chaitanya, S. Walsh, J.D. Andersen, R. Ansell, K. Ballantyne, D. Ballard, et al., Collaborative EDNAP exercise on the IrisPlex system for DNA-based prediction of human eye colour. Foren Sci Int Genet, 2014. 11: p. 241-251.

37. K.L. Hart, S.L. Kimura, V. Mushailov, Z.M. Budimlija, M. Prinz, and E. Wurmbach, Improved eyeand skin-color prediction based on 8 SNPs. Croat Med J, 2013. 54(3): p. 248-256.

38. O. Spichenok, Z. Budimlija, A. Mitchell, A. Jenny, L. Kovacevic, D. Marjanovic, et al., Prediction of eye and skin color in diverse populations using seven SNPs. Foren Sci Int Genet, 2011. 5: p. 472 478.

39. V. Mushailov, S.A. Rodriguez, Z.M. Budimlija, M. Prinz, and E. Wurmbach, Assay Development and Validation of an 8-SNP Multiplex Test to Predict Eye and Skin Coloration. J Foren Sci, 2015. 60(4): p. 990-1000.

40. J.S. Allwood and S. Harbison, SNP model development for the prediction of eye colour in New Zealand. Foren Sci Int Genet. 7(4): p. 444-452.

41. Y. Ruiz, C. Phillips, A. Gomez-Tato, J. Alvarez-Dios, M. Casares de Cal, R. Cruz, et al., Further development of forensic eye color predictive tests. Foren Sci Int Genet, 2013. 7: p. 28 - 40.

42. J. Sochtig, C. Phillips, O. Maronas, A. Gomez-Tato, R. Cruz, J. Alvarez-Dios, et al., Exploration of SNP variants affecting hair colour prediction in Europeans. Int J Legal Med, 2015. 129(5): p. 96375.

43. M. Edwards, A. Bigham, J. Tan, S. Li, A. Gozdzik, K. Ross, et al., Association of the OCA2 Polymorphism His615Arg with Melanin Content in East Asian Populations: Further Evidence of Convergent Evolution of Skin Pigmentation. PLOS Genetics, 2010. 6(3): p. e1000867.

44. E. Pośpiech, A. Wojas-Pelc, S. Walsh, F. Liu, H. Maeda, T. Ishikawa, et al., The common occurrence of epistasis in the determination of human pigmentation and its impact on DNA-based pigmentation phenotype prediction. Foren Sci Int Genet. 11: p. 64-72.

45. Scientific Working Group on DNA Analysis Methods (SWGDAM), Revised validation guidelines. Forensic Sci. Commun. , 2004. 6(3).

46. A. Untergasser, H. Nijveen, X. Rao, T. Bisseling, R. Geurts, and J.A. Leunissen, Primer3Plus, an enhanced web interface to Primer3. Nucleic Acids Res, 2007. 35: p. W71-4.

47. P.M. Vallone and J.M. Butler, AutoDimer: a screening tool for primer-dimer and hairpin structures. Biotechniques, 2004. 37(2): p. 226-31.

48. A. Erler, M. Stoneking, and M. Kayser, Development of Y-chromosomal microsatellite markers for nonhuman primates. Mol Ecol, 2004. 13(10): p. 2921-2930.

49. N.A. Rosenberg, Standardized subsets of the HGDP-CEPH Human Genome Diversity Cell Line Panel, accounting for atypical and duplicated samples and pairs of close relatives. Ann Hum Genet, 2006. 70(Pt 6): p. 841-7.

50. C. The 1000 Genomes Project, A global reference for human genetic variation. Nature, 2015. 526: p. 68.

51. B. Budowle, S.E. Schmedes, and F.R. Wendt, Increasing the reach of forensic genetics with massively parallel sequencing. Foren Sci Med Pathol, 2017. 13(3): p. 342-349.

52. Scientific Working Group on DNA Analysis Methods (SWGDAM), SWGDAM Interpretation Guidelines for Autosomal STR Typing by Forensic DNA Testing Laboratories. 2017. Available at http://www.swgdam.org. .

53. N.G. Crawford, D.E. Kelly, M.E.B. Hansen, M.H. Beltrame, S. Fan, S.L. Bowman, et al., Loci associated with skin pigmentation identified in African populations. Science, 2017.

54. A.R. Martin, M. Lin, J.M. Granka, J.W. Myrick, X. Liu, A. Sockell, et al., An Unexpectedly Complex Architecture for Skin Pigmentation in Africans. Cell. 171(6): p. 1340-1353.e14.

55. A. Caliebe, S. Walsh, F. Liu, M. Kayser, and M. Krawczak, Likelihood ratio and posterior odds in forensic genetics: Two sides of the same coin. Foren Sci Int Genet, 2017. 28: p. 203-210. 


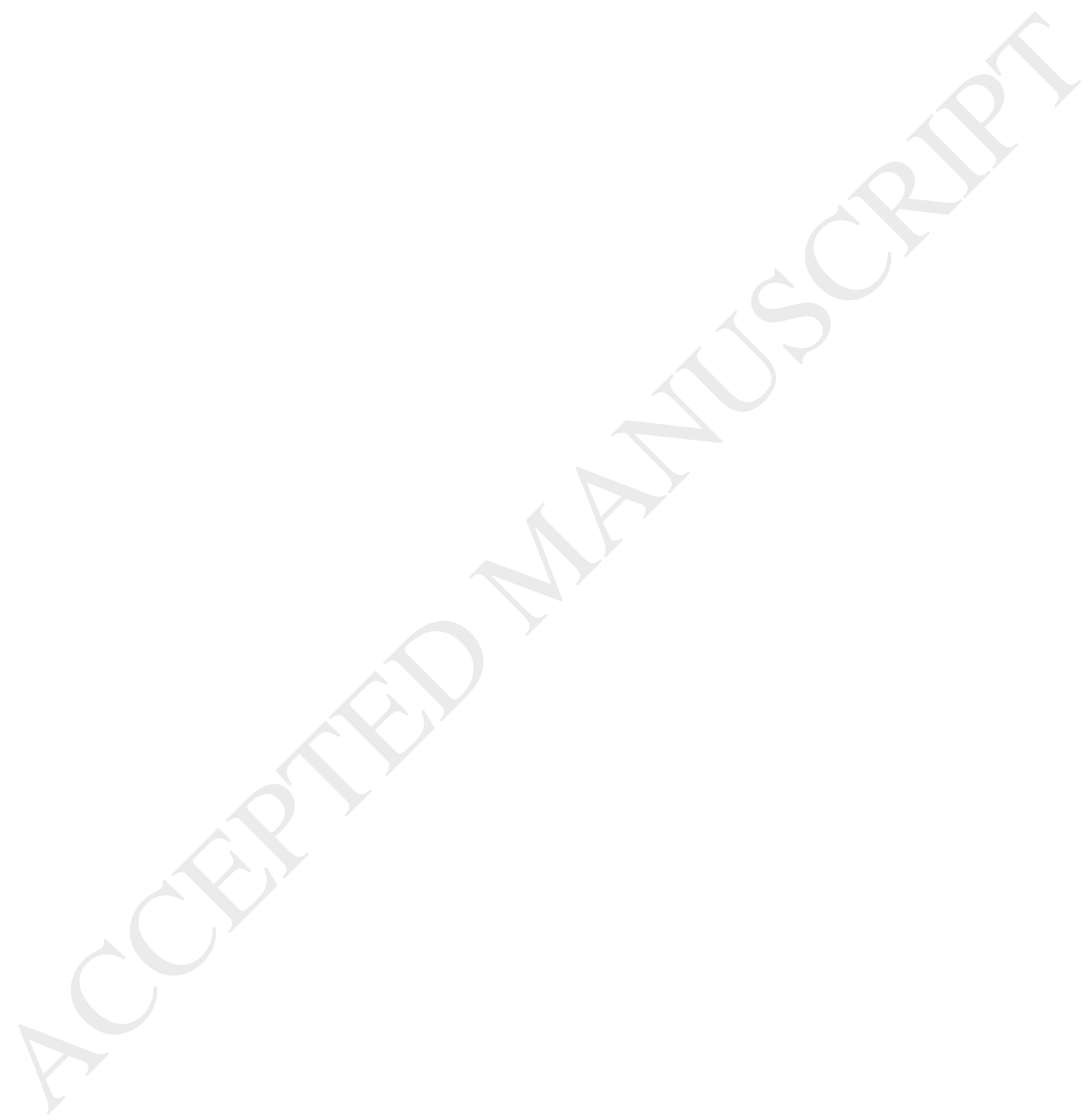




\section{Figures Legend}

Figure 1: Sensitivity testing with the 17-plex assay of the HIrisPlex-S DNA test system. DNA samples from three individuals with different skin colour phenotypes and different SNP genotypes ranging from 1 ng to 32 pg DNA input were used. Individual 1 displayed phenotypic dark skin colour, individual 2 displayed phenotypic intermediate skin colour, and individual 3 displayed phenotypic pale skin colour. The sensitivity threshold was established at $63 \mathrm{pg}$, which equals that previously obtained for the 24-plex HIrisPlex assay. Allele dropouts highlighted by black circles were observed at 32pg in all three individuals, but not at any higher input DNA concentrations.

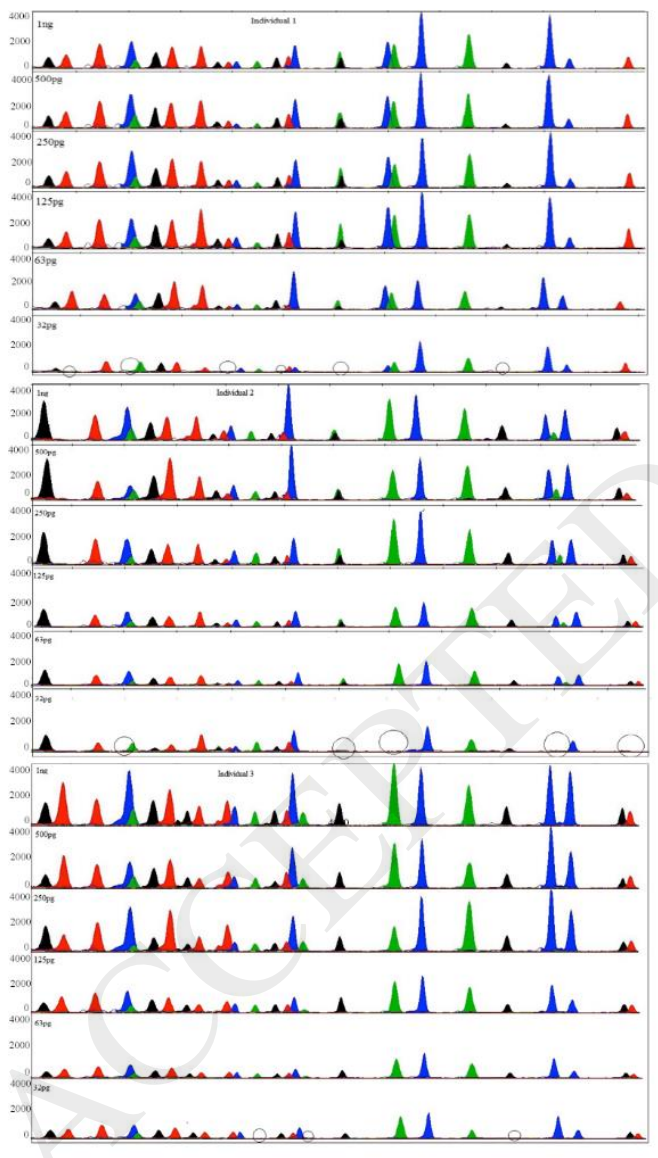


Figure 2: Homozygote and heterozygote testing with the 17-plex assay of the HIrisPlex-S DNA test system. Average peak height obtained from 20 replicates for each of the 10 test individuals using $250 \mathrm{pg}$ of DNA input in the HIrisPlex-S assay are shown. Samples were run with an ABI 3130xl Genetic Analyser, using POP-7 on a $36 \mathrm{~cm}$ capillary length array. The T/T homozygote allele of rs3114908 (SNP1), and rs6059655 (SNP14), the C/C homozygote allele of rs17128291 (SNP5) and rs6119471 (SNP12), and the A/A homozygote allele from rs1126809 (SNP9) and rs3212355 (SNP16) are absent from 2(A) and the heterozygote SNP profile of ra1800414 (SNP2) and rs3212355 (SNP16) are absent in 2(B). Error bars represent $95 \%$ standard error of the averages. The number at the bottom of each of the bars in 2(A) and 2(B) indicates the number of individuals in which the respective allele(s) was observed in the 10 test individuals.
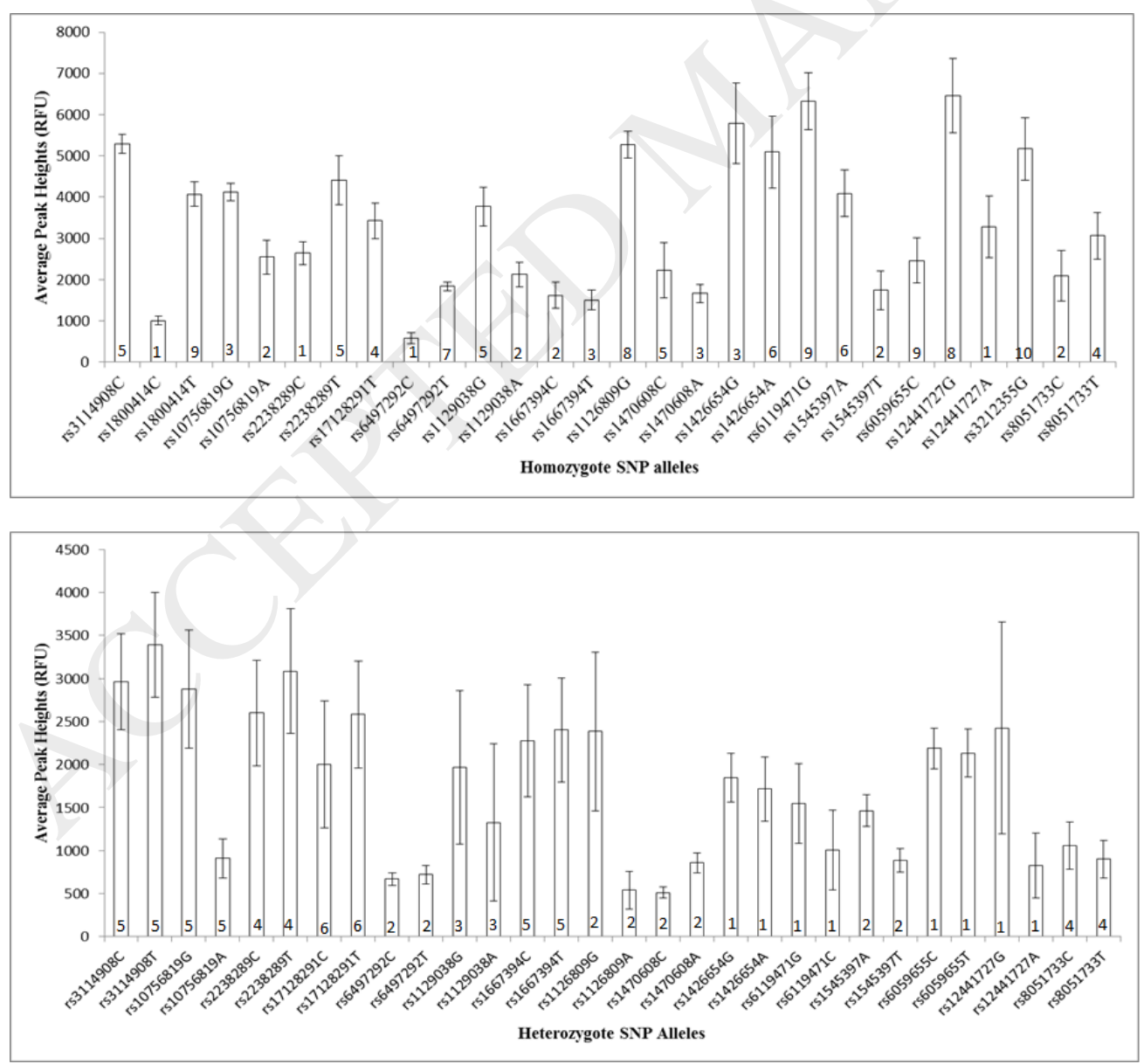
Figure 3: Mixture analysis with the 17-plex assay of the HIrisPlex-S DNA test system. We used 1:1, 1:5 and 1:10 mixtures from DNA samples of two individuals with different skin colour phenotypes and different HIrisPlex-S genotypes, individual 1 had phenotypic dark skin colour, and individual 2 had phenotypic pale skin colour. DNA used was approximately $500 \mathrm{pg}$ per individual. The asterisks represent peak height imbalance indicative of possible DNA mixture.

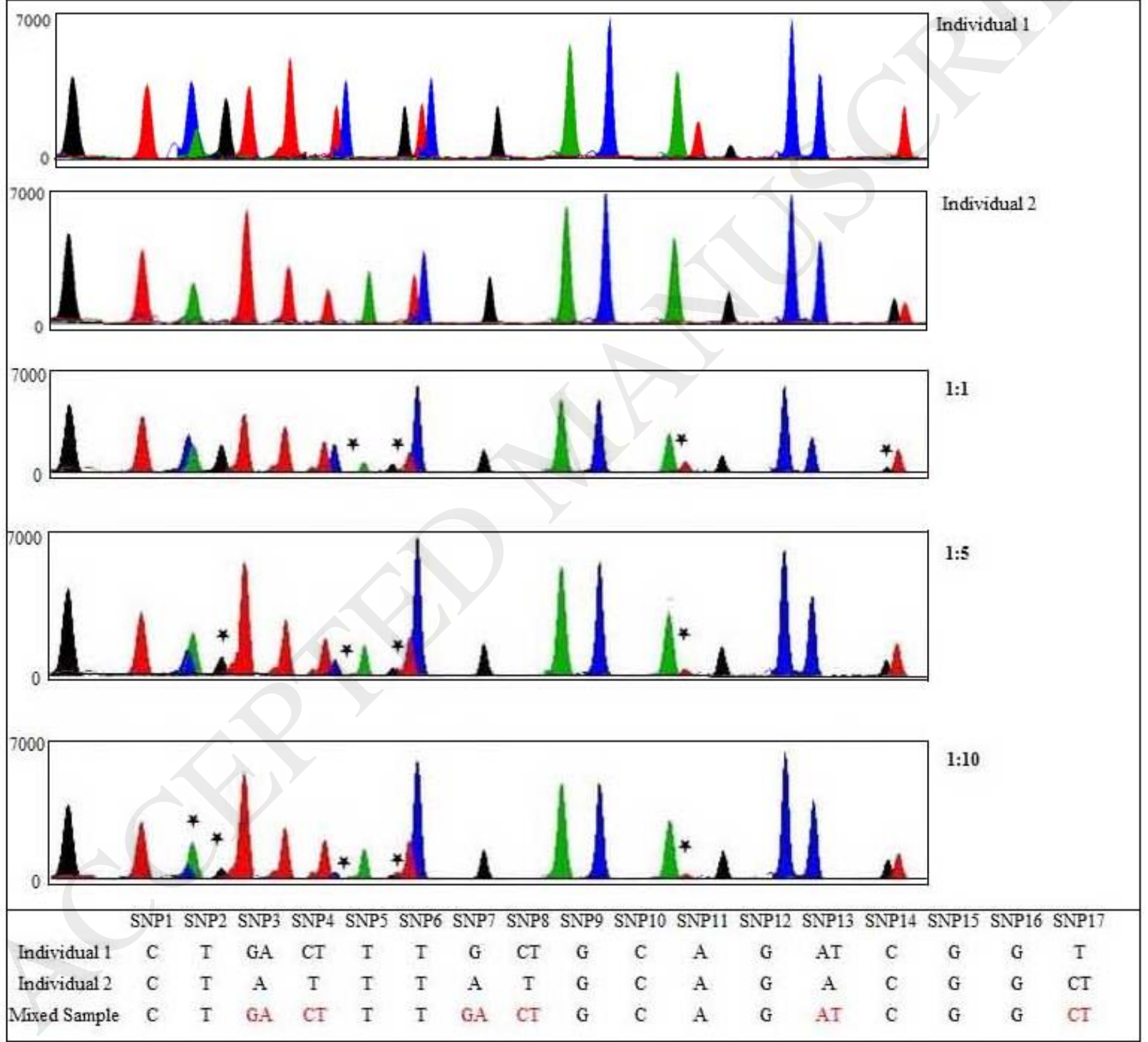


Figure 4: Global skin colour prediction with the HIrisPlex-S DNA test system. In total, 1539 individuals from 59 global populations were used, that were 762 samples from 51 populations of the HGDP-CEPH panel, and additional data from 777 individuals from 8 populations of the 1000 Genomes Project (IBS, FIN, ACB, CLM, GBR, KHV, PEL, PUR) were selected to fill geographic gaps as much as possible. Each individual is predicted to be one of five skin-colour categories; Very Pale, Pale, Intermediate, Dark and Dark-Black, with the highest probability used as finally predicted skin colour category. The MapViewer 7 (Golden Software, Inc., Golden, CO, USA) package was used to plot this distribution. Europe, Israel, Pakistan, China \& Mongolia were enlarged to give a better view of the skin colour predictions observed in populations from those regions. The size of the pie charts represented the number of individuals analysed in the respective population sample.

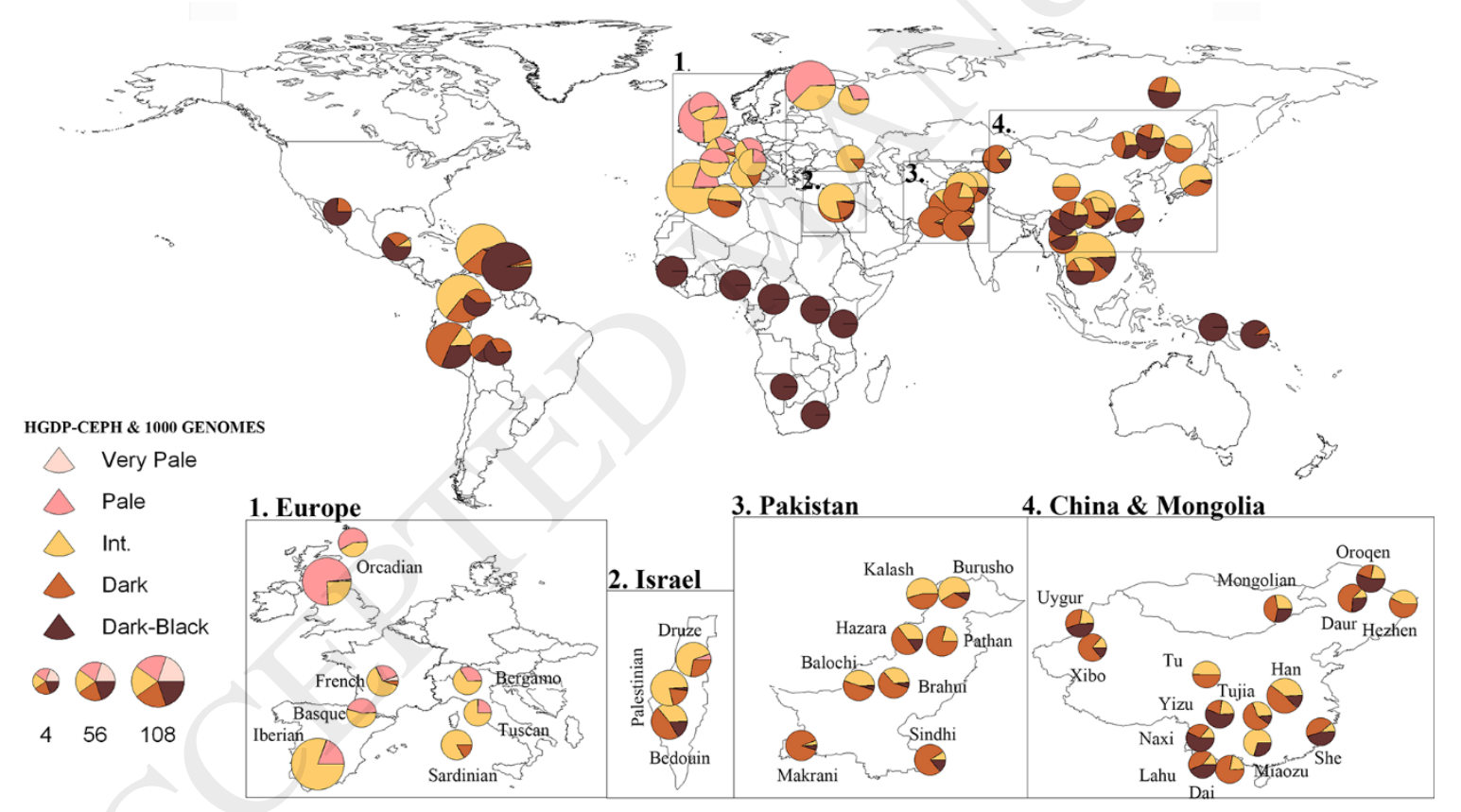


Figure 5: Illustrative example of the performance of the skin colour prediction model provided with the HIrisPlex-S DNA test system. In total, 35 individuals from 8 different countries (USA, Ireland, China, Mexico, Nigeria, Rwanda, India, El Salvador) were used. The individual skin images were ordered according to the increase in the highest prediction probabilities of the respective skin colour categories from the top left hand corner to the bottom right hand corner and in the skin colour direction from Very Pale to Dark-Black. Image ordering was completely independent from skin colour phenotypes. These individuals were not used for building and validating the HIrisPlex-S skin colour prediction model.

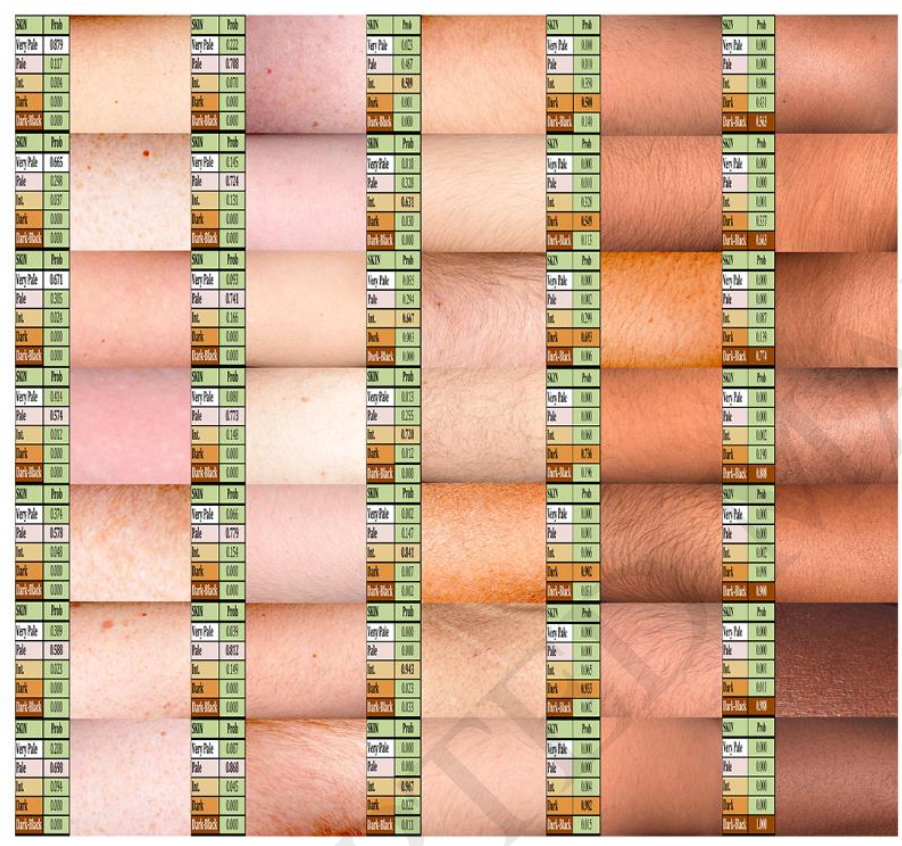


Figure 6: Illustrative examples of the influence the second highest probability category has together with the highest probability category on skin colour prediction provided with the HIrisPlex-S DNA test system. Example 1 highlights the effect of the second highest probability (Very Pale (A) or Intermediate (B)) influencing the highest probability Pale prediction for those two individuals. Example 2 highlights the effect of the second highest probability (Intermediate (C) or Dark-Black (D)) influencing the highest probability Dark prediction for those two individuals. We recommend (see Table 2) taking the highest together with the second highest probability category into account for finally concluding the most likely categorical skin colour with the HIrisPlex-S DNA test system.

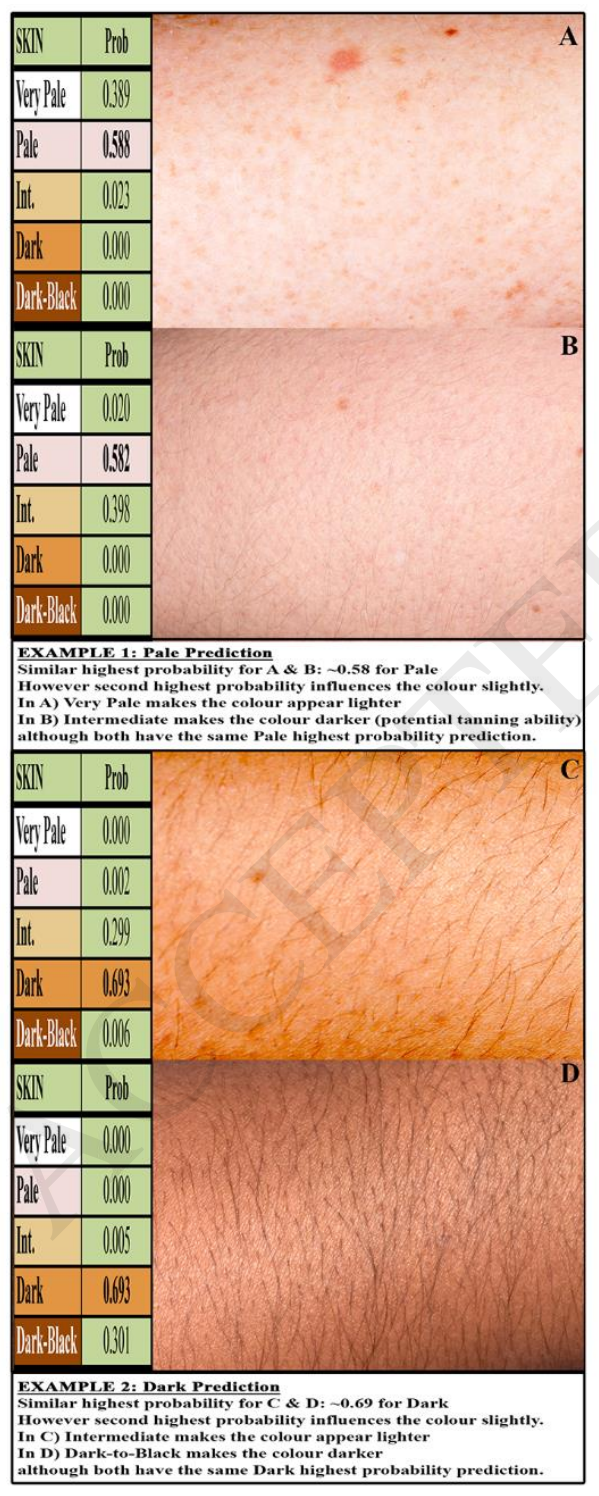




\section{Tables}

Table 1. The novel 17-plex assay from the HIrisPlex-S DNA test system with PCR and SBE primer sequences and concentration.

\begin{tabular}{|c|c|c|c|c|c|c|c|c|c|c|c|c|}
\hline $\begin{array}{l}\text { As } \\
\text { sa } \\
y \\
\text { Po } \\
\text { siti } \\
\text { on }\end{array}$ & $\begin{array}{l}\text { PCR } \\
\text { Prim } \\
\text { ers } \\
\end{array}$ & $\begin{array}{l}\text { B } \\
\text { as } \\
\text { es }\end{array}$ & Sequence & $\begin{array}{c}\text { Conc } \\
\text { entra } \\
\text { tion }\end{array}$ & Product Size & $\begin{array}{l}\text { SBE } \\
\text { Prim } \\
\text { ers }\end{array}$ & $\begin{array}{l}\text { Ge } \\
\text { ne }\end{array}$ & $\begin{array}{l}\text { NC } \\
\text { BI } \\
\text { dir } \\
\text { ect } \\
\text { ion }\end{array}$ & $\begin{array}{c}\text { H } \\
\text { PS } \\
\text { m } \\
\text { o } \\
\text { de } \\
\text { I } \\
\text { in } \\
p \\
\text { ut }\end{array}$ & $\begin{array}{l}\text { B } \\
\text { as } \\
\text { es }\end{array}$ & Sequence & $\begin{array}{c}\text { Conc } \\
\text { entra } \\
\text { tion } \\
\end{array}$ \\
\hline 1 & $\begin{array}{c}\text { rs311 } \\
4908 \\
\text { F }\end{array}$ & $\begin{array}{l}2 \\
0\end{array}$ & $\begin{array}{l}\text { CAGAACACAGC } \\
\text { CACACCCTA }\end{array}$ & $\begin{array}{l}0.4 \\
\mu \mathrm{m}\end{array}$ & $118 b p$ & $\begin{array}{c}\text { rs311 } \\
4908 \\
\text { R }\end{array}$ & $\begin{array}{c}\text { AN } \\
\text { KR } \\
\text { D1 } \\
1\end{array}$ & Rev & $\begin{array}{l}\mathrm{C} / \\
\mathrm{T}\end{array}$ & $\begin{array}{l}2 \\
9\end{array}$ & $\begin{array}{l}\text { TTTTTTTTTTAGAGAAGGGTCAAGCACT } \\
\mathrm{T}\end{array}$ & $\begin{array}{l}0.12 \\
\mu \mathrm{m}\end{array}$ \\
\hline & $\begin{array}{c}\text { rs311 } \\
4908 \\
\text { R } \\
\end{array}$ & $\begin{array}{l}2 \\
0 \\
\end{array}$ & $\begin{array}{l}\text { CATAAAGGGG } \\
\text { TCACCAGCAA }\end{array}$ & $\begin{array}{l}0.4 \\
\mu \mathrm{m}\end{array}$ & & & & & & & & \\
\hline & & & $Y$ & & & & & & & & & \\
\hline 2 & $\begin{array}{c}\text { rs180 } \\
0414 \\
\text { F } \\
\end{array}$ & $\begin{array}{l}2 \\
0 \\
\end{array}$ & $\begin{array}{l}\text { GCTGCAGGAG } \\
\text { TCAGAAGGTT }\end{array}$ & $\begin{array}{l}0.4 \\
\mu \mathrm{m}\end{array}$ & $145 b p$ & $\begin{array}{c}\mathrm{rs} 180 \\
0414 \\
\quad \mathrm{R} \\
\end{array}$ & $\begin{array}{l}\mathrm{OC} \\
\mathrm{A} 2\end{array}$ & Rev & $\begin{array}{l}\mathrm{T} / \\
\mathrm{C}\end{array}$ & $\begin{array}{l}4 \\
3\end{array}$ & $\begin{array}{l}\text { TTT TTT TTT TTC AGA ATC CCG TCA } \\
\text { GAT ATC CTA }\end{array}$ & $\begin{array}{l}0.2 \\
\mu \mathrm{m}\end{array}$ \\
\hline & $\begin{array}{c}\text { rs180 } \\
0414 \\
\quad \mathrm{R} \\
\end{array}$ & $\begin{array}{l}2 \\
0\end{array}$ & $\begin{array}{l}\text { GGGACAAACG } \\
\text { AATTGAGGAA }\end{array}$ & $\begin{array}{l}0.4 \\
\mu \mathrm{m}\end{array}$ & & & & & & & & \\
\hline 3 & $\begin{array}{c}\text { rs107 } \\
5681 \\
9 \_F\end{array}$ & $\begin{array}{l}2 \\
0\end{array}$ & $\begin{array}{l}\text { AAAGCAAGCTC } \\
\text { ATGTTTCCA }\end{array}$ & $\begin{array}{l}0.4 \\
\mu \mathrm{m}\end{array}$ & $145 b p$ & $\begin{array}{c}\text { rs107 } \\
5681 \\
\text { 9_F }\end{array}$ & $\begin{array}{l}\mathrm{BN} \\
\mathrm{C} 2\end{array}$ & $\begin{array}{c}\text { Fw } \\
d\end{array}$ & $\begin{array}{l}\text { A/ } \\
G\end{array}$ & $\begin{array}{l}3 \\
5\end{array}$ & $\begin{array}{l}\text { TTTTTTTTTTTTTGGACCAGTTATTTTTGGG } \\
\text { TTTGGA }\end{array}$ & $\begin{array}{l}1.7 \\
\mu \mathrm{m}\end{array}$ \\
\hline
\end{tabular}




\begin{tabular}{|c|c|c|c|c|c|c|c|c|c|c|c|c|}
\hline & $\begin{array}{c}r s 107 \\
5681 \\
\text { 9_R } \\
\end{array}$ & $\begin{array}{l}2 \\
3 \\
\end{array}$ & $\begin{array}{c}\text { CGTCATGACTA } \\
\text { GAAAAACACCA } \\
\text { A }\end{array}$ & $\begin{array}{l}0.4 \\
\mu \mathrm{m}\end{array}$ & & & 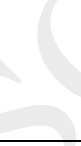 & & & & & \\
\hline & & & & & & & & & & & & \\
\hline 4 & $\begin{array}{c}r s 223 \\
8289 \\
F\end{array}$ & $\begin{array}{l}2 \\
1\end{array}$ & $\begin{array}{l}\text { GGAACATGAA } \\
\text { GATTTCCCAGT }\end{array}$ & $\begin{array}{l}0.4 \\
\mu \mathrm{m}\end{array}$ & $112 b p$ & $\begin{array}{l}\text { rs223 } \\
8289 \\
\text { F }\end{array}$ & $\begin{array}{l}\mathrm{HE} \\
\mathrm{RC} 2\end{array}$ & Rev & $\begin{array}{l}\mathrm{C} / \\
\mathrm{T}\end{array}$ & $\begin{array}{l}5 \\
3\end{array}$ & $\begin{array}{l}\text { TTT TTT TTT TTT TTT TTT TTG AGA } \\
\text { TTG GAA GAT TGG AGC C }\end{array}$ & $\begin{array}{l}0.5 \\
\mu \mathrm{m}\end{array}$ \\
\hline & $\begin{array}{c}\text { rs } 223 \\
8289 \\
\quad R \\
\end{array}$ & $\begin{array}{l}2 \\
2\end{array}$ & $\begin{array}{l}\text { CTGATTCAGGT } \\
\text { CTGCTGTCACT }\end{array}$ & $\begin{array}{l}0.4 \\
\mu \mathrm{m}\end{array}$ & & & & & & & & \\
\hline 5 & $\begin{array}{c}\text { rs171 } \\
2829 \\
1 \_F \\
\end{array}$ & $\begin{array}{l}2 \\
0\end{array}$ & $\begin{array}{l}\text { CCAGCACTGCC } \\
\text { AAAATAACA }\end{array}$ & $\begin{array}{l}0.4 \\
\mu \mathrm{m}\end{array}$ & $129 \mathrm{bp}$ & $\begin{array}{c}\text { rs171 } \\
2829 \\
1 \_R \\
\end{array}$ & $\begin{array}{l}\text { SLC } \\
24 \\
\text { A4 } \\
\end{array}$ & $\begin{array}{c}\text { Fw } \\
d\end{array}$ & $\begin{array}{l}\mathrm{T} / \\
\mathrm{C}\end{array}$ & $\begin{array}{l}5 \\
8\end{array}$ & $\begin{array}{l}\text { TTT TTT TTT TTT TTT TTT TTT CAA TGT } \\
\text { GCA CTG GAT TAA AAG TC }\end{array}$ & $1 \mu \mathrm{m}$ \\
\hline & $\begin{array}{c}\text { rs } 171 \\
2829 \\
1 \_R \\
\end{array}$ & $\begin{array}{l}2 \\
0\end{array}$ & $\begin{array}{l}\text { CTCTTTGGACC } \\
\text { CATCACCTC }\end{array}$ & $\begin{array}{l}0.4 \\
\mu \mathrm{m}\end{array}$ & & & & & & & & \\
\hline 6 & $\begin{array}{c}\text { rs649 } \\
7292 \\
\text { F }\end{array}$ & $\begin{array}{l}2 \\
1\end{array}$ & $\begin{array}{l}\text { TCTGCTGTAGA } \\
\text { ACCAATGTCC }\end{array}$ & $\begin{array}{l}0.4 \\
\mu \mathrm{m}\end{array}$ & 150bp & $\begin{array}{c}r s 649 \\
7292 \\
\text { R }\end{array}$ & $\begin{array}{l}\mathrm{HE} \\
\mathrm{RC} 2\end{array}$ & $\begin{array}{c}\text { Fw } \\
\text { d }\end{array}$ & $\begin{array}{l}\text { T/ } \\
\mathrm{C}\end{array}$ & $\begin{array}{l}6 \\
1\end{array}$ & $\begin{array}{l}\text { TTT TTT TTT TTT TTT TTT TTT TTT TTG } \\
\text { TCT CCT GTG TCT TCA TCC T }\end{array}$ & $\begin{array}{l}0.2 \\
\mu \mathrm{m}\end{array}$ \\
\hline & $\begin{array}{c}r 649 \\
7292 \\
{ }_{-} \mathrm{R} \\
\end{array}$ & $\begin{array}{l}2 \\
1\end{array}$ & $\begin{array}{l}\text { GAATTGCACCT } \\
\text { GTAGCTCCAT }\end{array}$ & $\begin{array}{l}0.4 \\
\mu \mathrm{m}\end{array}$ & & & & & & & & \\
\hline D & & & & & & & & & & & & \\
\hline 7 & $\begin{array}{c}\mathrm{rs} 112 \\
9038 \\
\mathrm{~F}\end{array}$ & $\begin{array}{l}2 \\
0\end{array}$ & $\begin{array}{l}\text { ATGTCGACTCC } \\
\text { TTTGCTTCG }\end{array}$ & $\begin{array}{l}0.4 \\
\mu \mathrm{m}\end{array}$ & $137 b p$ & $\begin{array}{c}\mathrm{rs} 112 \\
9038 \\
\mathrm{~F}\end{array}$ & $\begin{array}{l}\mathrm{HE} \\
\mathrm{RC} 2\end{array}$ & Rev & $\begin{array}{l}\text { A/ } \\
G\end{array}$ & $\begin{array}{l}7 \\
0\end{array}$ & $\begin{array}{l}\text { TTT TTT TTT TTT TTT TTT TTT TTT TTT } \\
\text { TTT TTT TTT GAG CCA GGC AGC AGA } \\
\text { GC }\end{array}$ & $\begin{array}{l}0.4 \\
\mu \mathrm{m}\end{array}$ \\
\hline & $\begin{array}{c}\mathrm{rs} 112 \\
9038 \\
{ }_{-} \mathrm{R}\end{array}$ & $\begin{array}{l}2 \\
0\end{array}$ & $\begin{array}{c}\text { ACACCAGGCAG } \\
\text { CCTACAGTC }\end{array}$ & $\begin{array}{l}0.4 \\
\mu \mathrm{m}\end{array}$ & & & & & & & & \\
\hline & & & & & & & & & & & & \\
\hline
\end{tabular}




\begin{tabular}{|c|c|c|c|c|c|c|c|c|c|c|c|c|}
\hline 8 & $\begin{array}{c}\text { rs166 } \\
7394 \\
\text { F }\end{array}$ & $\begin{array}{l}2 \\
4\end{array}$ & $\begin{array}{c}\text { CAGCTGTAGAG } \\
\text { AGAGACTTTGA } \\
\text { GG }\end{array}$ & $\begin{array}{l}0.4 \\
\mu \mathrm{m}\end{array}$ & $130 \mathrm{bp}$ & $\begin{array}{c}\text { rs166 } \\
7394 \\
\quad R\end{array}$ & $\begin{array}{l}\mathrm{HE} \\
\mathrm{RC} 2\end{array}$ & Rev & $\begin{array}{l}\mathrm{C} / \\
\mathrm{T}\end{array}$ & $\begin{array}{l}7 \\
3\end{array}$ & $\begin{array}{l}\text { TTT TTT TTT TTT TTT TTT TTT TTT TTT } \\
\text { TTT TTT GCA GCA ATT CAA AAC GTG } \\
\text { CAT A }\end{array}$ & $\begin{array}{l}0.2 \\
\mu \mathrm{m}\end{array}$ \\
\hline & $\begin{array}{c}\text { rs166 } \\
7394 \\
\quad R \\
\end{array}$ & $\begin{array}{l}2 \\
0\end{array}$ & $\begin{array}{c}\text { CACCATTAAGA } \\
\text { CGCAGCAAT }\end{array}$ & $\begin{array}{l}0.4 \\
\mu \mathrm{m}\end{array}$ & & & & & & & & \\
\hline & & & & & & & & & & & & \\
\hline 9 & $\begin{array}{c}\mathrm{rs} 112 \\
6809 \\
\ldots\end{array}$ & $\begin{array}{l}2 \\
7\end{array}$ & $\begin{array}{l}\text { TGTTTCTTAGTC } \\
\text { TGAATAACCTT } \\
\text { TTCC }\end{array}$ & $\begin{array}{l}0.4 \\
\mu \mathrm{m}\end{array}$ & $100 \mathrm{bp}$ & $\begin{array}{c}r s 112 \\
6809 \\
\ldots\end{array}$ & TYR & $\begin{array}{c}\text { Fw } \\
d\end{array}$ & $\begin{array}{l}A / \\
G\end{array}$ & $\begin{array}{l}7 \\
7\end{array}$ & $\begin{array}{l}\text { TTT TTT TTT TTT TTT TTT TTT TTT TTT } \\
\text { TTT TTT TTT TGT ATT TTT GAG CAG } \\
\text { TGG CTC C }\end{array}$ & $\begin{array}{c}0.05 \\
\mu \mathrm{m}\end{array}$ \\
\hline & $\begin{array}{c}\mathrm{rs} 112 \\
6809 \\
\quad \mathrm{R}\end{array}$ & $\begin{array}{l}2 \\
0 \\
\end{array}$ & $\begin{array}{c}\text { GGTGCATTGGC } \\
\text { TTCTGGATA }\end{array}$ & $\begin{array}{l}0.4 \\
\mu \mathrm{m}\end{array}$ & & & & & & & & \\
\hline 10 & $\begin{array}{c}\text { rs147 } \\
0608 \\
\text { F }\end{array}$ & $\begin{array}{l}2 \\
6\end{array}$ & $\begin{array}{l}\text { TTTCTTGTGTTA } \\
\text { ACTGTCCTTAC } \\
\text { AAA }\end{array}$ & $\begin{array}{l}0.4 \\
\mu \mathrm{m}\end{array}$ & $145 b p$ & $\begin{array}{c}r s 147 \\
0608 \\
F\end{array}$ & $\begin{array}{l}\mathrm{OC} \\
\mathrm{A} 2\end{array}$ & Rev & $\begin{array}{l}\text { A/ } \\
\text { C }\end{array}$ & $\begin{array}{l}6 \\
2\end{array}$ & $\begin{array}{l}\text { TTT TTT TTT TTT TTT TTT TTT TTT TTT } \\
\text { TTT TTC ATT CTC TCT TAA AAA TAT } \\
\text { TAA TTT GCA CC }\end{array}$ & $4 \mu \mathrm{m}$ \\
\hline & $\begin{array}{c}\mathrm{rs} 147 \\
0608 \\
\quad \mathrm{R}\end{array}$ & $\begin{array}{l}2 \\
3 \\
\end{array}$ & $\begin{array}{c}\text { GGAAAATATGT } \\
\text { TAGGGTTGATG } \\
\text { G } \\
\end{array}$ & $\begin{array}{l}0.4 \\
\mu \mathrm{m}\end{array}$ & & & & & & & & \\
\hline 11 & $\begin{array}{c}\text { rs142 } \\
6654 \\
\ldots\end{array}$ & $\begin{array}{l}2 \\
0\end{array}$ & $\begin{array}{c}\text { TTCAGCCCTTG } \\
\text { GATTGTCTC }\end{array}$ & $\begin{array}{l}0.4 \\
\mu \mathrm{m}\end{array}$ & $123 b p$ & $\begin{array}{c}\mathrm{rs} 142 \\
6654 \\
\ldots\end{array}$ & $\begin{array}{l}\text { SLC } \\
24 \\
\text { A5 }\end{array}$ & $\begin{array}{c}\mathrm{Fw} \\
\mathrm{d}\end{array}$ & $\begin{array}{l}A / \\
G\end{array}$ & $\begin{array}{l}8 \\
6\end{array}$ & $\begin{array}{l}\text { TTT TTT TTT TTT TTT TTT TTT TTT TTT } \\
\text { TTT TTT TTT TTT TIT TTT TGT CTC } \\
\text { AGG ATG TTG CAG GC }\end{array}$ & $\begin{array}{c}0.16 \\
\mu \mathrm{m}\end{array}$ \\
\hline & $\begin{array}{c}\mathrm{rs} 142 \\
6654 \\
{ }_{-} \mathrm{R}\end{array}$ & $\begin{array}{l}2 \\
6\end{array}$ & $\begin{array}{l}\text { TGAGTAAGCAA } \\
\text { GAAGTATAAG } \\
\text { GAGCA }\end{array}$ & $\begin{array}{l}0.4 \\
\mu \mathrm{m}\end{array}$ & & & & & & & & \\
\hline 12 & $\begin{array}{c}\text { rs611 } \\
9471 \\
\ldots\end{array}$ & $\begin{array}{l}2 \\
0\end{array}$ & $\begin{array}{l}\text { GCAGGAGAAT } \\
\text { TGCTGGAACT }\end{array}$ & $\begin{array}{l}0.4 \\
\mu \mathrm{m}\end{array}$ & $170 \mathrm{bp}$ & $\begin{array}{c}\mathrm{rs} 611 \\
9471 \\
{ }_{\mathrm{R}}\end{array}$ & $\begin{array}{c}\text { ASI } \\
P\end{array}$ & $\begin{array}{c}\mathrm{Fw} \\
\mathrm{d}\end{array}$ & $\begin{array}{l}\mathrm{G} / \\
\mathrm{C}^{*}\end{array}$ & $\begin{array}{l}9 \\
1\end{array}$ & $\begin{array}{l}\text { TTT TTT TTT TTT TTT TTT TTT TTT TTT } \\
\text { TTT TTT TTT TTT TTT TTT TGA AGG } \\
\text { AAG AGT GAA AAT GCG TAA }\end{array}$ & $1 \mu \mathrm{m}$ \\
\hline
\end{tabular}




\begin{tabular}{|c|c|c|c|c|c|c|c|c|c|c|c|c|}
\hline & $\begin{array}{c}\text { rs611 } \\
9471 \\
\quad \mathrm{R} \\
\end{array}$ & $\begin{array}{l}2 \\
1 \\
\end{array}$ & $\begin{array}{c}\text { AACCCGAAGG } \\
\text { AAGAGTGAAA } \\
\text { A } \\
\end{array}$ & $\begin{array}{l}0.4 \\
\mu \mathrm{m}\end{array}$ & & & 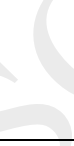 & & & & & \\
\hline & & & & & & & 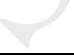 & & & & & \\
\hline 13 & $\begin{array}{c}\text { rs154 } \\
5397 \\
\ldots\end{array}$ & $\begin{array}{l}2 \\
4 \\
\end{array}$ & $\begin{array}{c}\text { GGTATAGGATT } \\
\text { ATTTGGGGAAT } \\
\text { GA } \\
\end{array}$ & $\begin{array}{l}0.4 \\
\mu \mathrm{m}\end{array}$ & $144 b p$ & $\begin{array}{c}\mathrm{rs} 154 \\
5397 \\
\ldots\end{array}$ & $\begin{array}{l}\mathrm{OC} \\
\mathrm{A} 2\end{array}$ & $\begin{array}{c}\text { Fw } \\
d\end{array}$ & $\begin{array}{l}\mathrm{A} / \\
\mathrm{T}\end{array}$ & $\begin{array}{l}9 \\
7 \\
\end{array}$ & $\begin{array}{l}\text { TTT TTT TTT TTT TTT TTT TTT TTT TTT } \\
\text { TTT TTT TTT TTT TTT TTT GTA CAA CTT } \\
\text { TGT GAA TAT ACT AAA ATA C }\end{array}$ & $1 \mu \mathrm{m}$ \\
\hline & $\begin{array}{c}\text { rs154 } \\
5397 \\
\quad R\end{array}$ & $\begin{array}{l}2 \\
8\end{array}$ & $\begin{array}{c}\text { TGGAGATATAG } \\
\text { AATTCACACAA } \\
\text { CATAAA }\end{array}$ & $\begin{array}{l}0.4 \\
\mu \mathrm{m}\end{array}$ & & & & & & & & \\
\hline 14 & $\begin{array}{c}\text { rs605 } \\
9655 \\
\ldots \\
\end{array}$ & $\begin{array}{l}2 \\
0 \\
\end{array}$ & $\begin{array}{l}\text { GTGAGGAAAT } \\
\text { CGAGGCTCAG }\end{array}$ & $\begin{array}{l}0.4 \\
\mu \mathrm{m}\end{array}$ & $112 \mathrm{bp}$ & $\begin{array}{c}r s 605 \\
9655 \\
\quad R\end{array}$ & $\begin{array}{c}\text { RAL } \\
Y\end{array}$ & $\begin{array}{c}\text { Fw } \\
d\end{array}$ & $\begin{array}{l}A / \\
G\end{array}$ & $\begin{array}{l}7 \\
6 \\
\end{array}$ & $\begin{array}{l}\text { TTTTTTTTTTTTTTTTTTTTTTTTTTTTTT } \\
\text { TTTTTTTTTTTTTTTTTTTTTTTTTTTTGC } \\
\text { TGATGCCCTGAGCA }\end{array}$ & $2 \mu \mathrm{m}$ \\
\hline & $\begin{array}{c}\text { rs605 } \\
9655 \\
\quad R \\
\end{array}$ & $\begin{array}{l}2 \\
0\end{array}$ & $\begin{array}{c}\text { AGGAGAAAGC } \\
\text { TGCAGATCCA }\end{array}$ & $\begin{array}{l}0.4 \\
\mu \mathrm{m}\end{array}$ & & & & & & & & \\
\hline 15 & $\begin{array}{c}\text { rs124 } \\
4172 \\
7 \_F\end{array}$ & $\begin{array}{l}2 \\
0\end{array}$ & $\begin{array}{l}\text { GGGAAGAGAC } \\
\text { AGCTCCATGT }\end{array}$ & $\begin{array}{l}0.4 \\
\mu \mathrm{m}\end{array}$ & $137 b p$ & $\begin{array}{c}\text { rs124 } \\
4172 \\
7 \_F\end{array}$ & $\begin{array}{l}\mathrm{OC} \\
\mathrm{A} 2\end{array}$ & $\begin{array}{c}\text { Fw } \\
d\end{array}$ & $\begin{array}{c}\text { A/ } \\
G\end{array}$ & $\begin{array}{l}1 \\
0 \\
6\end{array}$ & $\begin{array}{l}\text { TTT TTT TTT TTT TTT TTT TTT TTT TTT } \\
\text { TTT TTT TTT TTT TTT TTT TTT TTT TTT } \\
\text { TTT TTT TTT TGG CTC AGT GTG GCC } \\
\text { TT }\end{array}$ & $\begin{array}{l}0.5 \\
\mu \mathrm{m}\end{array}$ \\
\hline & $\begin{array}{c}\text { rs124 } \\
4172 \\
7 \_R\end{array}$ & $\begin{array}{l}2 \\
0\end{array}$ & $\begin{array}{c}\text { ACAATCCTGGG } \\
\text { AGGTACACG }\end{array}$ & $\begin{array}{l}0.4 \\
\mu \mathrm{m}\end{array}$ & & & & & & & & \\
\hline & & & & & & & & & & & & \\
\hline 16 & $\begin{array}{c}\text { rs321 } \\
2355 \\
\quad F \\
\end{array}$ & $\begin{array}{l}2 \\
0 \\
\end{array}$ & $\begin{array}{c}\text { GAGTGAACCCA } \\
\text { GGAAGATGC }\end{array}$ & $\begin{array}{l}0.4 \\
\mu \mathrm{m}\end{array}$ & $144 b p$ & $\begin{array}{r}r s 321 \\
2355 \\
\quad R\end{array}$ & $\begin{array}{l}\mathrm{MC} \\
1 \mathrm{R} \\
\end{array}$ & $\begin{array}{c}\text { Fw } \\
d\end{array}$ & $\begin{array}{l}\mathrm{T} / \\
\mathrm{C}\end{array}$ & $\begin{array}{l}1 \\
1 \\
3 \\
\end{array}$ & $\begin{array}{l}\text { TTT TTT TTT TTT TTT TTT TTT TTT TTT } \\
\text { TTT TTT TTT TTT TTT TTT TTT TTT TTT } \\
\text { TTT TTT TTT TTT TTT TCC GAA GCC } \\
\text { CAG CAG G }\end{array}$ & $\begin{array}{l}1.5 \\
\mu \mathrm{m}\end{array}$ \\
\hline & $\begin{array}{c}\text { rs321 } \\
2355 \\
\text { R }\end{array}$ & $\begin{array}{l}2 \\
0\end{array}$ & $\begin{array}{l}\text { CATCAAAGGCA } \\
\text { GACCTCTCG }\end{array}$ & $\begin{array}{l}0.4 \\
\mu \mathrm{m}\end{array}$ & & & & & & & & \\
\hline
\end{tabular}




\begin{tabular}{|c|c|c|c|c|c|c|c|c|c|c|c|c|}
\hline 17 & $\begin{array}{c}\text { rs805 } \\
1733 \\
\ldots F\end{array}$ & $\begin{array}{l}1 \\
9\end{array}$ & $\begin{array}{l}\text { AGGCGGTGGT } \\
\text { СТСTCTCTC }\end{array}$ & $\begin{array}{l}0.4 \\
\mu \mathrm{m}\end{array}$ & $124 \mathrm{bp}$ & $\begin{array}{c}\text { rs805 } \\
1733 \\
\_\end{array}$ & $\begin{array}{c}\text { DEF } \\
8\end{array}$ & Fw & $\begin{array}{l}\mathrm{T} / \\
\mathrm{C}\end{array}$ & $\begin{array}{l}1 \\
1 \\
5\end{array}$ & $\begin{array}{l}\text { TTT TTT TTT TTT TTT TTT TTT TTT TTT } \\
\text { TTT TTT TTT TTT TTT TTT TTT TTT TTT } \\
\text { TTT TTT TTT TTT TTT TTC ACC CTG CCT } \\
\text { GTC TCG }\end{array}$ & $\begin{array}{l}1.6 \\
\mu \mathrm{m}\end{array}$ \\
\hline & $\begin{array}{c}\text { rs805 } \\
1733 \\
R\end{array}$ & $\begin{array}{l}2 \\
0\end{array}$ & $\begin{array}{c}\text { TTGCAACAGGA } \\
\text { GGGTCTAGG }\end{array}$ & $\begin{array}{l}0.4 \\
\mu \mathrm{m}\end{array}$ & & & & & & & & \\
\hline
\end{tabular}

*When using the HPS assay, the minor allele to add is C if present, but when using sequencing data that uses NCBI forward design and forward primer, you must flip strand of your sequence result before inputting the $C$ allele if present 
Table 2. Preliminary prediction guide for the interpretation of skin colour probability values and thresholds obtained with the HIrisPlex-S DNA test system.

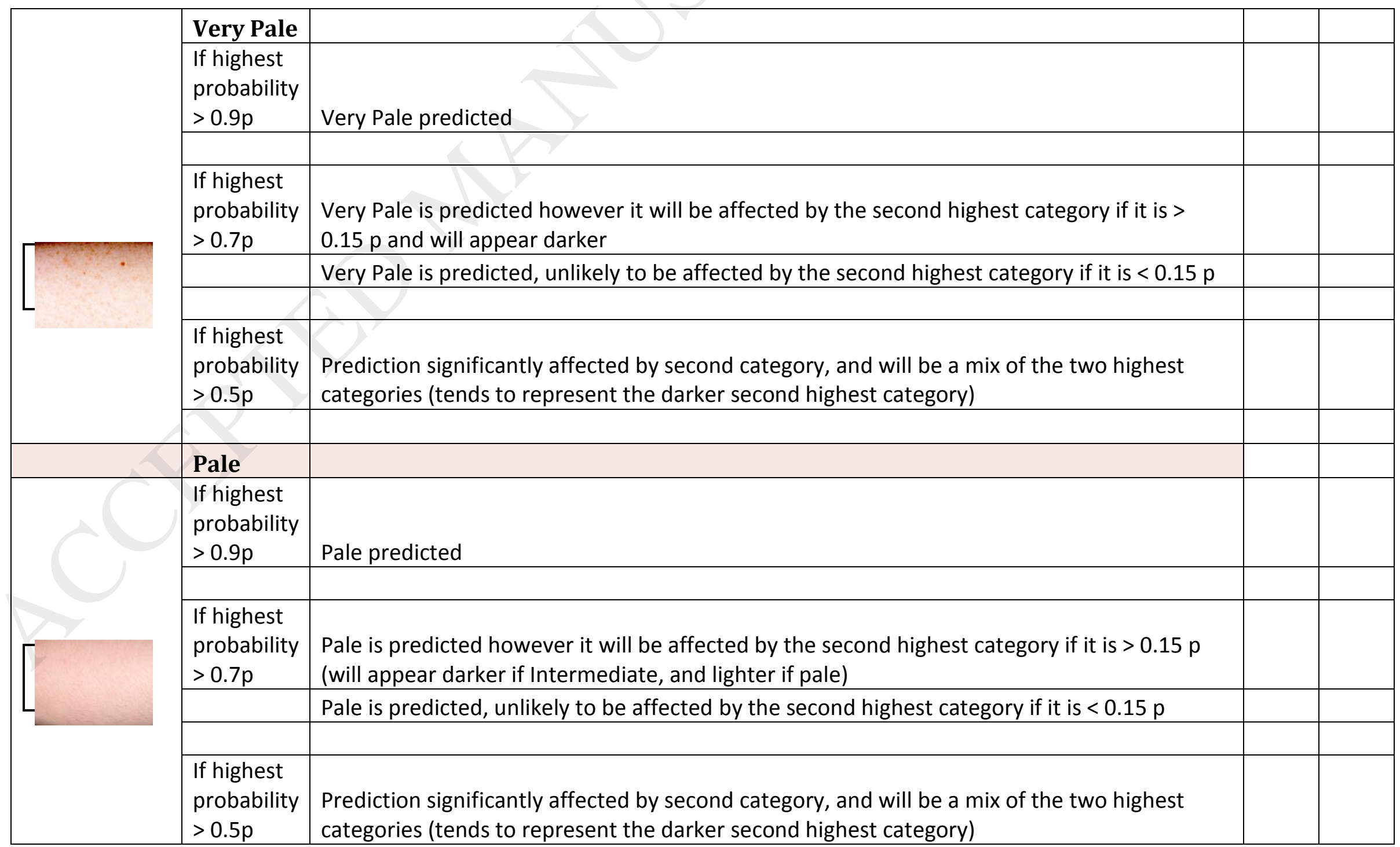




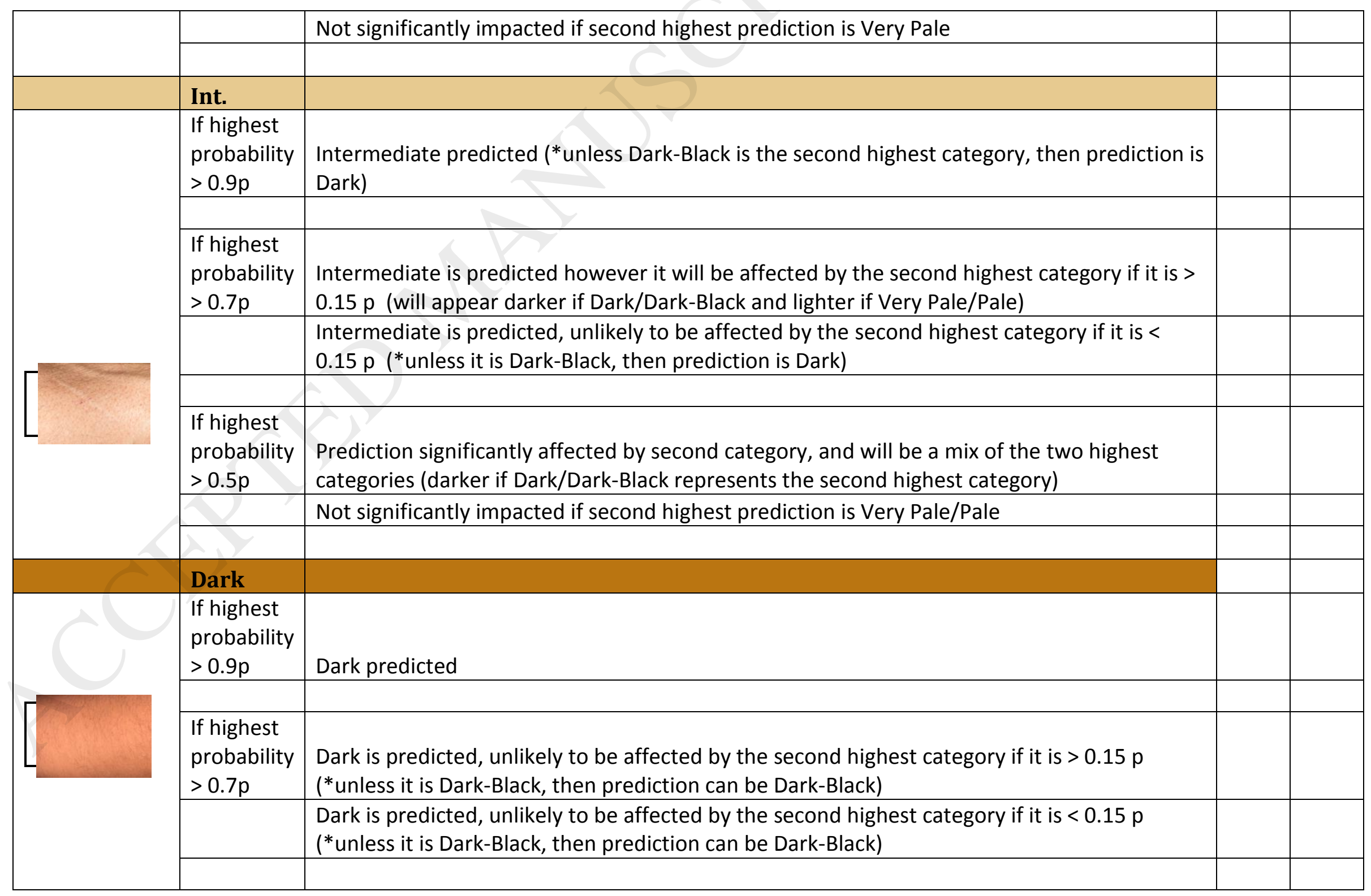




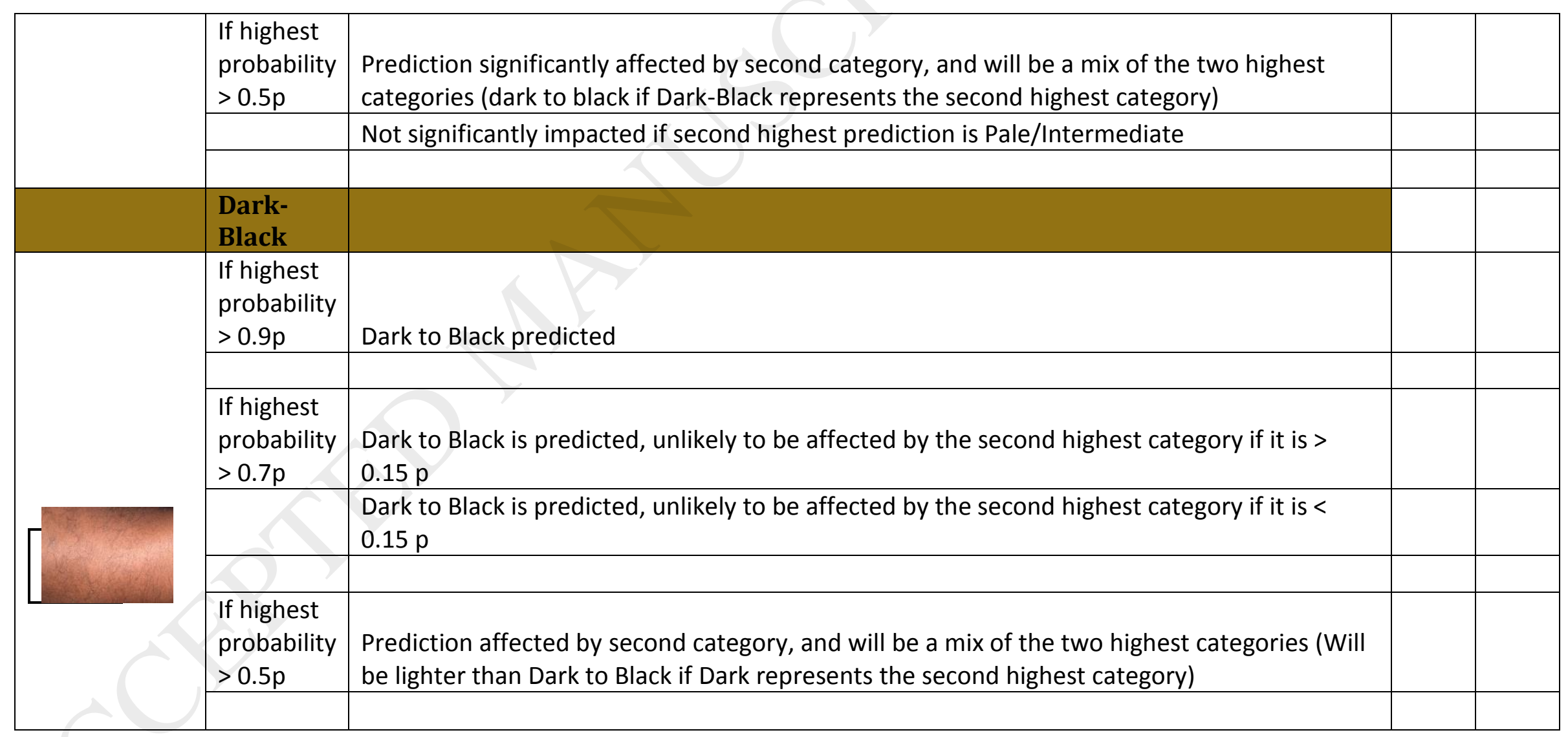

